\title{
Platinum Monolayer Electrocatalysts for the Oxygen Reduction Reaction: Improvements Induced by Surface and Subsurface Modifications of Cores
}

\author{
Yun Cai and Radoslav R. Adzic \\ Department of Chemistry, Brookhaven National Laboratory, Upton, NY 11973, USA \\ Correspondence should be addressed to Radoslav R. Adzic, adzic@bnl.gov \\ Received 18 May 2011; Accepted 22 August 2011 \\ Academic Editor: Wolfgang Schmickler
}

Copyright ( $) 2011$ Y. Cai and R. R. Adzic. This is an open access article distributed under the Creative Commons Attribution License, which permits unrestricted use, distribution, and reproduction in any medium, provided the original work is properly cited.

This paper demonstrates that the ORR activity of $\mathrm{Pt}_{\mathrm{ML}}$ electrocatalysts can be further improved by the modification of surface and subsurface of the core materials. The removal of surface low-coordination sites, generation (via addition or segregation) of an interlayer between $\mathrm{Pt}_{\mathrm{ML}}$ and the core, or the introduction of a second metal component to the subsurface layer of the core can further improve the ORR activity and/or stability of $\mathrm{Pt}_{\mathrm{ML}}$ electrocatalysts. These modifications generate the alternation of the interactions between the substrate and the $\mathrm{Pt}_{\mathrm{ML}}$, involving the changes on both electronic (ligand) and geometric (strain) properties of the substrates. The improvements resulted from the application of these approaches provide a new perspective to designing of the new generation $\mathrm{Pt}_{\mathrm{ML}}$ electrocatalysts.

\section{Introduction}

Fuel cells are considered to be one of the most promising clean energy technologies that can help resolve the energy crisis and problems of environmental pollution. However, the promise of their widespread application is seriously hindered by the necessarily high content of Pt in the cathode catalysts and the slow kinetics of oxygen reduction reaction on the best available Pt-based catalysts. New catalysts are needed that reduce considerably the Pt content while affording the possibility of enhanced catalytic activity. In recent years, we developed a new approach for designing and synthesizing electrocatalysts that significantly reduce the Pt content and surpass the oxygen reduction reaction (ORR) activity of the state-of-the-art carbon-supported Pt electrocatalysts [1]. These electrocatalysts consist of a monolayer of Pt on carbon-supported metal or metal-alloy nanoparticles and has the highest utilization of Pt since almost every Pt atom are present on the surface and participate in the electrocatalytic reactions. These electrocatalysts are referred as platinum monolayer $\left(\mathrm{Pt}_{\mathrm{ML}}\right)$ electrocatalysts.
The Pt monolayer deposition process involves the galvanic displacement of an underpotentially deposited $\mathrm{Cu}$ monolayer on a suitable substrate by Pt [2].

Since the first development, $\mathrm{Pt}_{\mathrm{ML}}$ electrocatalysts with various core materials were designed and synthesized for assorted reactions in fuel-cell applications [1,3-10]. Many of them exhibit excellent activities and stabilities. The interaction between the Pt monolayer and the substrate material has been demonstrated to induce a synergistic effect for ORR kinetics $[6,11-13]$. When Pt atoms deposit on a foreign metal, due to the difference in atomic radius, the Pt surface will undergo compressive or tensile strain. As illustrated in Figure 1 [1], Pt atoms deposited on a Ru substrate would have a large compressive strain, but they would have only a small compressive strain on Pd and a tensile strain when deposited on Au. Santos et al. also observed such strain effect and demonstrated a strong correlation between the strain and electrocatalytic activities [14]. D-band center shift induced by the surface strain has been demonstrated to be a major factor determining the catalysts' activity [15]. Moreover, electronic (ligand) effect from the electronic 


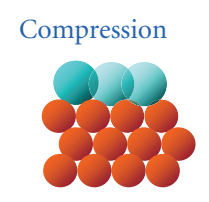

$\mathrm{Pt} / \mathrm{Ru}(0001)$

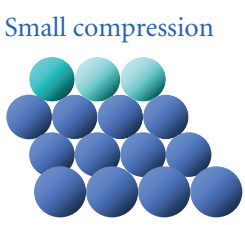

$\mathrm{Pt} / \mathrm{Pd}(111)$

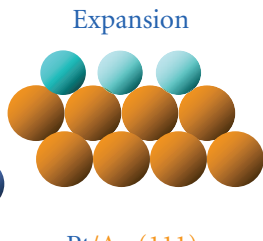

$\mathrm{Pt} / \mathrm{Au}(111)$
Figure 1: Models of pseudomorphic monolayers of Pt on three different substrates inducing compressive strain $(\mathrm{Ru}(0001)$ and $\operatorname{Pd}(111))$ and expansive strain $(\mathrm{Au}(111))[1]$.

coupling between $\mathrm{Pt}_{\mathrm{ML}}$ and its supporting substrate play an additional role in determining the catalytic activity [16]. Density functional theory (DFT) calculations have shown that the binding energies and reactivity of small adsorbates have a great correlation with the position of d-band center on strained surfaces and metal overlayers [17, 18]. The interaction with the proper substrate can also decrease the oxidation of Pt monolayer and thus enhance the stability of the catalyst.

In our earlier study (Figure 2) [6], we demonstrated that the electrocatalytic activity for ORR of Pt monolayer on six different single crystal surfaces has a volcano-type dependence on the position of their d-band center from DFT calculations. On the top of the "volcano" plot is the Pt monolayer on a $\operatorname{Pd}(111)$ surface, that is, the most active electrocatalyst among six Pt monolayer-substrate couples, plus the single $\mathrm{Pt}(111)$ surface. Our experiments on various Pt monolayer nanoparticles also demonstrated that the variation of the core materials significantly affect the performance of the catalyst $[1,3-10]$. Among the $\mathrm{Pt}_{\mathrm{ML}}$ electrocatalysts we studied for the ORR, the palladium and palladium alloy cores outperform the rest in terms of both activity and stability $[6,19]$.

Several unique features of $\mathrm{Pt}_{\mathrm{ML}}$ electrocatalysts open various possibilities for designing electrocatalysts with specific catalytic properties by choosing appropriate substrates. The strong dependence of the catalytic activity on the interaction between Pt monolayer and its substrate suggests that the electrocatalytic activity of Pt monolayer catalysts may be further improved via the modification of substrate materials. Since palladium and palladium alloy are the best candidates as a substrate to support $\mathrm{Pt}_{\mathrm{ML}}$, they will be our major focus in the efforts of achieving further enhanced activity and stability. In the ORR kinetics, the reaction rate is either limited by the dissociation of $\mathrm{O}_{2}$ or the protonation of $\mathrm{O}_{2}$ for metal surface that binds oxygen too weakly, or by the removal of adsorbed $\mathrm{O}$ and $\mathrm{OH}$ species if the metal binds oxygen too strong [21]. In the case of Pd, the oxygen binding energy is still slightly higher than the optimum value for the ORR kinetics [16], therefore in the design of the new generation $\mathrm{Pt}_{\mathrm{ML}}$ electrocatalysts, we are targeting at fine-tuning the core materials to further weaker the oxygen binding on Pd substrate. In this review, we will describe several examples demonstrating the improvements of the $\mathrm{Pt}$ monolayer electrocatalysts for the ORR via the modifications of surface and subsurface of the core materials.

\section{Direct Modification of the Surface of the Core [22]}

Although the Pd(111) substrate for Pt monolayer has been demonstrated possessing an oxygen binding energy close to the optimum value, the nanoparticle Pd, however, exhibits much more difficulty in the removing of $\mathrm{OH}$ species due to the existence of considerable amount of low-coordination sites, edges, defects, adatoms, and so forth, which bind oxygen much stronger than that on terrace sites [23]. To obtain a smoother Pd nanoparticle surface, we developed a strategy, referred to as bromide treatment, to successfully remove significant amount of low-coordination sites on $\mathrm{Pd} / \mathrm{C}$ and $\mathrm{Pd}_{3} \mathrm{Co} / \mathrm{C}$ and produce more (111) facets while maintaining the particle size.

The schematic in Figure 3 illustrates how the bromide solution removes the atoms on low-coordination sites during the potential cycles. In brief, the process starts from the chemisorption of a bromine layer in an alkaline solution, followed by the reductive desorption of bromine. After immersing the electrode in the bromide-containing solution, $\mathrm{Br}^{-}$immediately is adsorbed on the surface, preferentially on the low-coordination sites, since the atoms on those sites bind with $\mathrm{Br}$ more strongly than those on terrace sites. In the cathodic scan, the reductive desorption of the bromine triggers the migration of low-coordinated Pd to terrace sites to minimize the total surface-free energy. Moreover, the reduction of $\mathrm{Br}$ to $\mathrm{Br}^{-}$introduces a positive charge in the adjacent $\mathrm{Pd}$, and the low-coordinated atoms have a looser structure than the high-coordinated ones. Hence, it is likely that the low-coordinated $\mathrm{Pd}$ forms a $\mathrm{Pd}-\mathrm{Br}_{2}$ pair in solution, that is, redeposited onto the surface in the following anodic scan, accompanied by the oxidative adsorption of bromide. Meanwhile, during the cycling, the adsorbed bromine layer undergoes rearrangement to attain the stable adlayer structure on a given surface, for example, $(\sqrt{3} \times \sqrt{3}) \mathrm{R} 30^{\circ}-\mathrm{Br}$ on $\mathrm{Pd}(111),(2 \times 2)-\mathrm{Br}$ on $\mathrm{Pd}(100)$ [24]. Therefore, during this Br-rearrangement on the surface, the adsorbed-Br may draw the dangling atoms to fill the defect sites to form a large terrace patches containing an ordered $\mathrm{Br}$ adlayer if the original terrace size is large enough to stabilize it.

Figure 4 shows the TEM images of palladium nanoparticles before and after bromide treatment. Various shapes of particles with obtruding edges are present in the commercial E-TEK sample. In contrast, the Br-treated Pd/C nanoparticles are rounded, and their size distribution is narrow.

The formation of a well-ordered 2D metal overlayer via UPD is known to depend on the substrate's crystallographic orientation and density of imperfection [25]. The less the amount of imperfections at the surface the better the formation of more ordered commensurate $2 \mathrm{D}$ phases is, provided that the atomic sizes are not too dissimilar. In this case, more $\mathrm{Pt}(111)$ 2D patches instead of 3D clusters would form on the bromide-treated surface, which in turn, should benefit the oxygen-reduction reaction.

Figure 5 shows the polarization curves for the ORR. The sample with $\mathrm{Pt}_{\mathrm{ML}}$ on $\mathrm{Br}$-treated-Pd/C nanoparticles shows significant enhancement of kinetics of the ORR, compared 


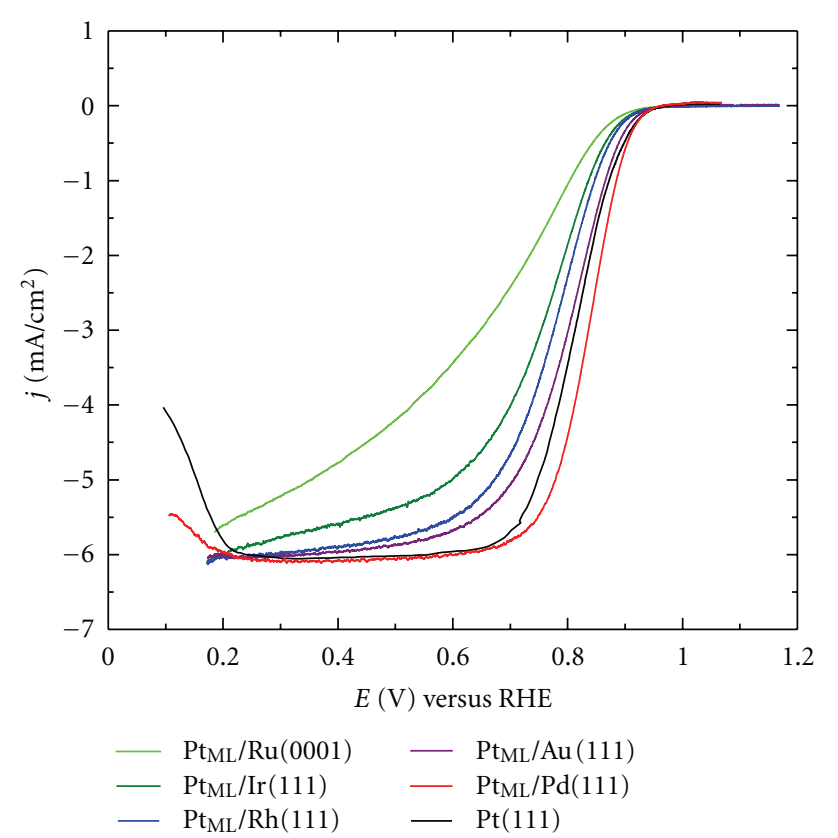

(a)

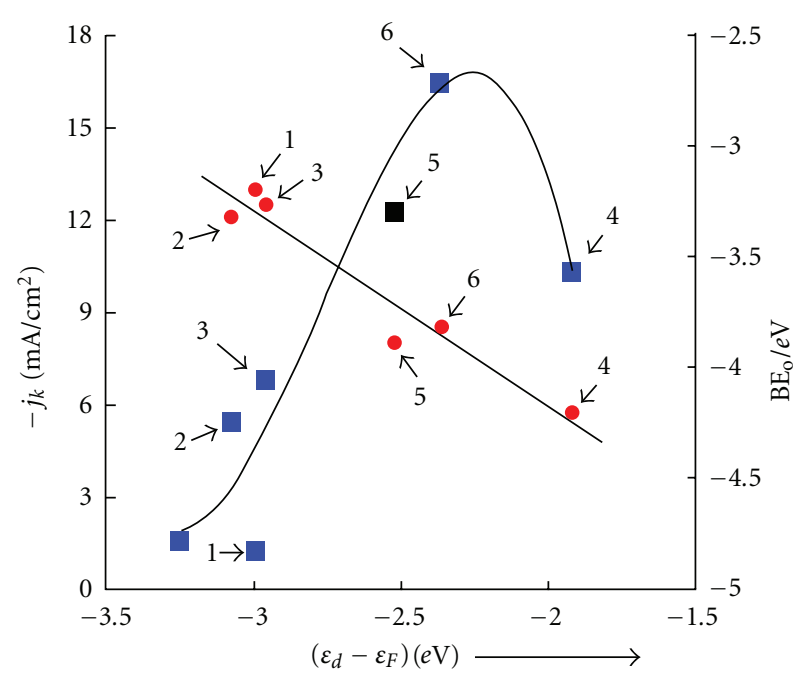

(b)

Figure 2: (a) Polarization curves for $\mathrm{O}_{2}$ reduction on platinum monolayers $\left(\mathrm{Pt}_{\mathrm{ML}}\right)$ on $\mathrm{Ru}(0001), \operatorname{Ir}(111), \mathrm{Rh}(111), \mathrm{Au}(111)$, and $\mathrm{Pd}(111)$ in a $0.1 \mathrm{M} \mathrm{HClO}_{4}$ solution on a disk electrode. The curve for $\mathrm{Pt}(111)$ is taken from $[19,20]$ and included for comparison. The rotation rate is $1600 \mathrm{rpm}$, and the sweep rate is $20 \mathrm{mVs}^{-1}\left(50 \mathrm{mVs}^{-1}\right.$ for $\left.\mathrm{Pt}(111)\right) ; j=$ current density, RHE = reverible hydrogen electrode [6]. (b) Kinetic currents ( $j_{K}$, square symbols) at $0.8 \mathrm{~V}$ for $\mathrm{O}_{2}$ reduction on the platinum monolayers supported on different single-crystal surfaces in a $0.1 \mathrm{M}$ $\mathrm{HClO}_{4}$ solution and calculated binding energies of atomic oxygen $\left(\mathrm{BE}_{\mathrm{o}}\right.$, filled circles) as functions of calculated d-band center $\left(\varepsilon_{\mathrm{d}}-\varepsilon_{\mathrm{F}}\right)$; relative to the Fermi level) of the respective clean platinum monolayers. The current data for $\mathrm{Pt}(111)$ is taken from $[19,20]$ and included for comparison. Labels: (1) $\mathrm{Pt}_{\mathrm{ML}} / \mathrm{Ru}$ (0001), (2) $\mathrm{Pt}_{\mathrm{ML}} / \mathrm{Ir}(111)$, (3) $\mathrm{Pt}_{\mathrm{ML}} / \mathrm{Rh}$ (111), (4) $\mathrm{Pt}_{\mathrm{ML}} / \mathrm{Au}(111)$, (5) $\mathrm{Pt}(111)$, and (6) $\mathrm{Pt}_{\mathrm{ML}} / \mathrm{Pd}(111)$ [6].

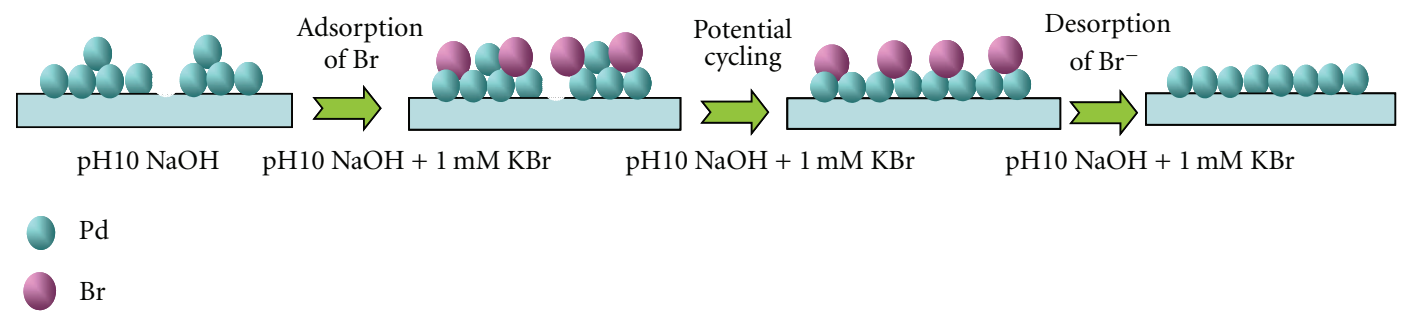

FIGURE 3: Illustration of the removal of surface low-coordination sites via the oxidative adsorption and reductive desorption of a bromine layer [22].

with the untreated nanoparticles, especially at potentials more negative than the half-wave potential (marked by a circle), the so-called combined diffusion-kinetic control region. In this region, the adsorption and dissociation of molecular oxygen competes with strongly adsorbed hydroxyl species $\left(\mathrm{OH}_{\mathrm{ads}}\right)$ for the same sites [20, 23, 26]. Furthermore, $\mathrm{OH}_{\mathrm{ads}}$ does not only block the active sites on Pt, but also changes the adsorption energy of intermediates adjacent to it formed during the reaction [20]. On a smooth surface, $\mathrm{OH}$ binding is less strong with respect to that on edge sites, and thus, the inhibition of the ORR kinetics decreases. We summarize the corresponding mass activity and specific activity for the ORR in the inset of Figure 5; 0.25 -fold and 0.5 -fold enhancements were found, respectively.
2.1. Br-Treatment of $\mathrm{Pd}_{3} \mathrm{Co} / \mathrm{C}$. The oxygen-reduction reaction on $\mathrm{Pt}_{\mathrm{ML}} / \mathrm{Pd} \mathrm{d}_{3} \mathrm{Co} / \mathrm{C}$ attained a Pt mass activity $2 \sim 3$-fold that of commercial Pt/C [7]. However, its poor stability due to the dissolution of Co hampered its industrial applications. Because the surface Co leaches during the reaction, more low-coordination sites are generated, thereby accelerating further dissolution of the $\mathrm{Co}$, and degrading the catalyst. Our bromide-treatments of $\mathrm{Pd} / \mathrm{C}$ nanoparticles demonstrated an excellent method of removing the low-coordination sites by having a bromine-adlayer and the resulting advantages for the ORR.

Figure 6 shows the morphologies of the original $\mathrm{Pd}_{3} \mathrm{Co} / \mathrm{C}$ nanoparticles, and of $\mathrm{Pt}_{\mathrm{ML}}$ on $\mathrm{Pd}_{3} \mathrm{Co} / \mathrm{C}$ after the $\mathrm{Br}$ treatment. The particles in the original $\mathrm{Pd}_{3} \mathrm{Co} / \mathrm{C}$ have average 


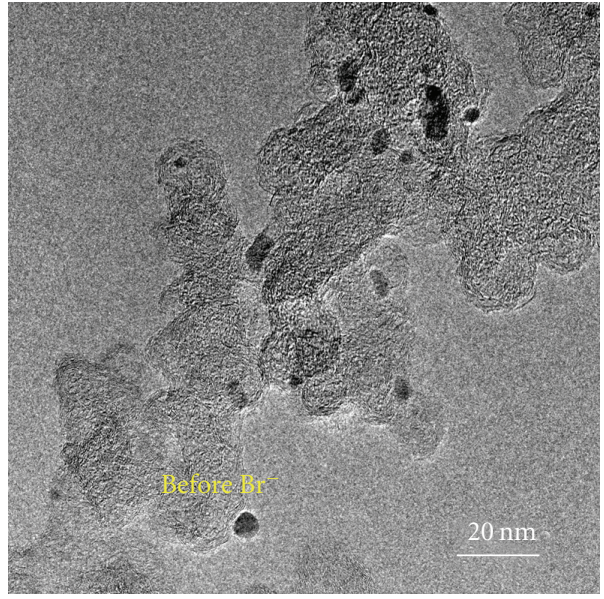

(a)

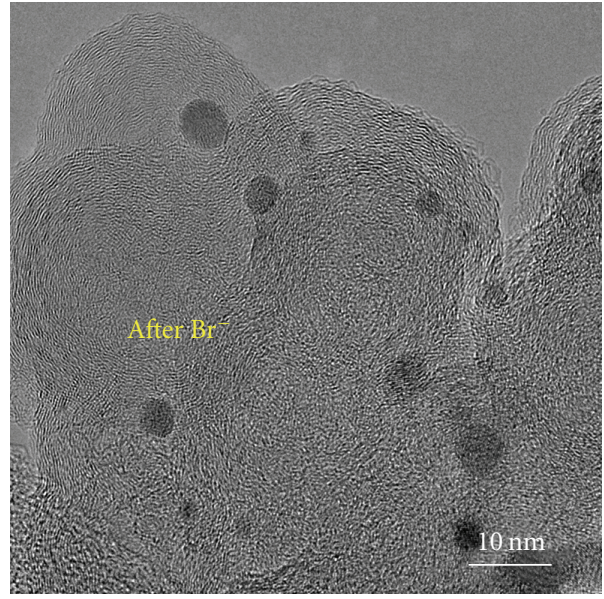

(b)

Figure 4: High-resolution TEM images of Pd/C before (a) and after (b) Br-treatment [22].

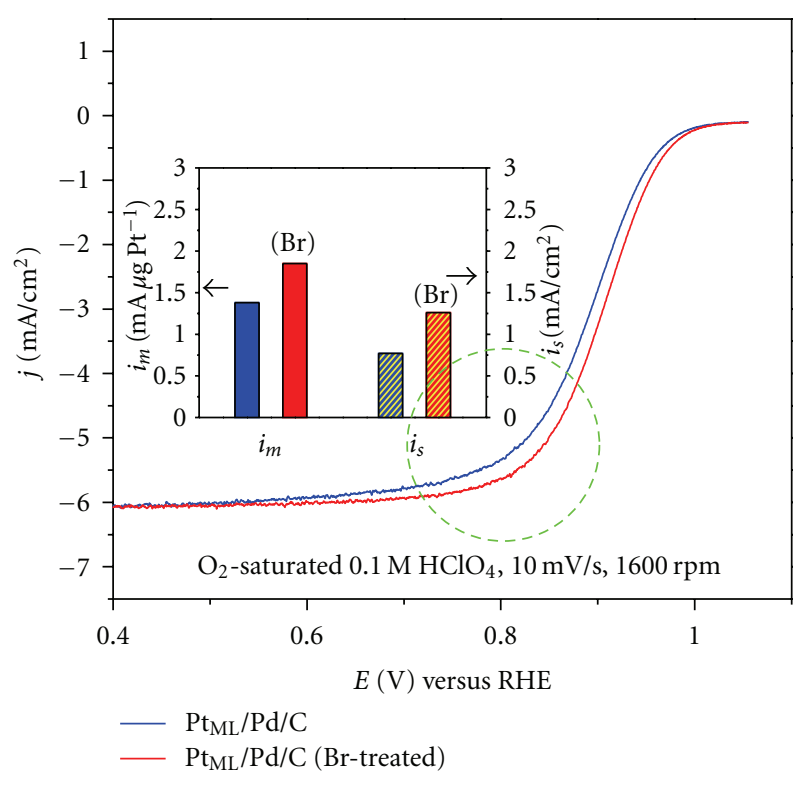

Figure 5: Polarization curves of oxygen reduction at $\mathrm{Pt}_{\mathrm{ML}}$ on $\mathrm{Br}-$ treated and -untreated $\mathrm{Pd} / \mathrm{C}$. Inset: comparison of mass activity and specific activity on $\mathrm{Pt}_{\mathrm{ML}} / \mathrm{Pd} / \mathrm{C}$ [22].

diameter of $4.25 \mathrm{~nm}$, but a wide size distribution, from 1.1 to $10 \mathrm{~nm}$. Many small particles with a diameter of $3 \mathrm{~nm}$ were present and considerable number of defects and edges on the particles are observed. The Pt monolayer catalysts supported on Br-treated $\mathrm{Pd}_{3} \mathrm{Co} / \mathrm{C}$ nanoparticles show a much more uniform particle size, averaging $5.8 \mathrm{~nm}$. Considering this size includes the thickness of a $\mathrm{Pt}$ monolayer, the average Br-treated $\mathrm{Pd}_{3} \mathrm{Co} / \mathrm{C}$ nanoparticles should be around $5.5 \mathrm{~nm}$ at most. The Br-treated nanoparticles exhibit a large area of well-defined (111)-crystalline structure, even after the deposition of the platinum monolayer while the untreated$\mathrm{Pd}_{3} \mathrm{Co} / \mathrm{C}$ particles have much smaller patches with poorly defined crystalline structures. Seemingly, after bromide treatment, most particles with diameters less than $3 \mathrm{~nm}$ dissolved and were redeposited on larger particles, suggesting the occurrence of Ostwald ripening [27] during the Brtreatment.

Figure 7 shows the $\mathrm{CV}$ and polarization curves for ORR on $\mathrm{Pt}_{\mathrm{ML}}$ catalysts supported on Br-treated $\mathrm{Pd}_{3} \mathrm{Co} / \mathrm{C}$ after various potential cycles. The activity and surface area remains unchanged after 25,000 potential cycles between 0.6 and $1.0 \mathrm{~V}$. It is a significant improvement of the stability since the same test with Johnson Matthey's $\mathrm{Pt}_{\mathrm{ML}} / \mathrm{Pd}_{3} \mathrm{Co} / \mathrm{C}$ resulted in a negative shift of the half-wave potential of more than $30 \mathrm{mV}$ in the first 5000 cycles.

The above examples of surface modifications of Pd and $\mathrm{Pd}_{3}$ Co core demonstrated that the removal of surface lowcoordination sites via bromide-treatment enables to obtain nanoparticles with smooth surfaces having a high density of (111)-oriented facets and a slightly contracted structure. The after-treated cores become excellent substrate for $\mathrm{Pt}$ monolayer and significant enhancements were realized of the mass activity and specific activity for the ORR.

\section{Addition of an Interlayer between the Pt Monolayer and the Core}

3.1. $P t_{M L} / P d / I r C o / C ~[28]$. Iridium is one of the most stable transition metals; its dissolution potential is comparable with platinum [29]. Its particular activity for the ORR is enhanced by alloying it with cobalt or platinum $[30,31]$. However, Ir is not a good support for a Pt monolayer because it causes the $\mathrm{Pt}$ lattice to contract too strongly, and consequently, significantly decreases the d-band center; that is, it lowers the reactivity of $\mathrm{Pt}$, entailing a very weak adsorption of $\mathrm{O}_{2}$ on $\mathrm{Pt}$ and a slow ORR kinetics [1, 6, 32]. Moreover, the relatively low ORR activity on Ir alone and its alloys, confirmed experimentally and theoretically, results from the disproportionately strong binding energy of oxygen at the surface [6]. Thus, it is a challenge to design an electrocatalytic system containing a highly stable and less expensive core, 


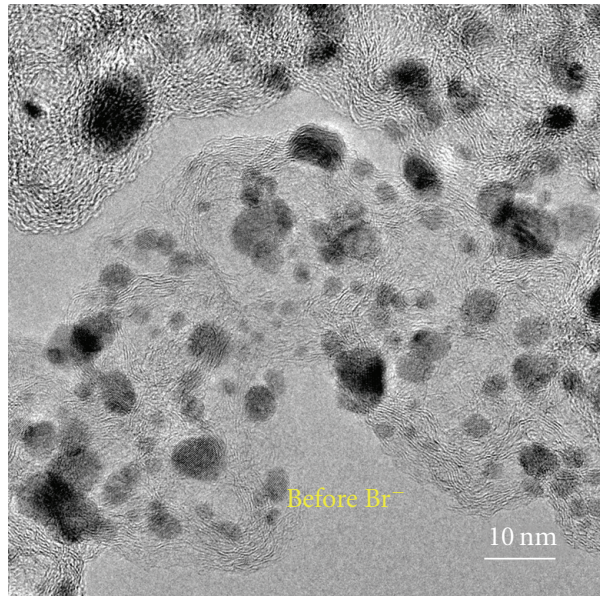

(a)

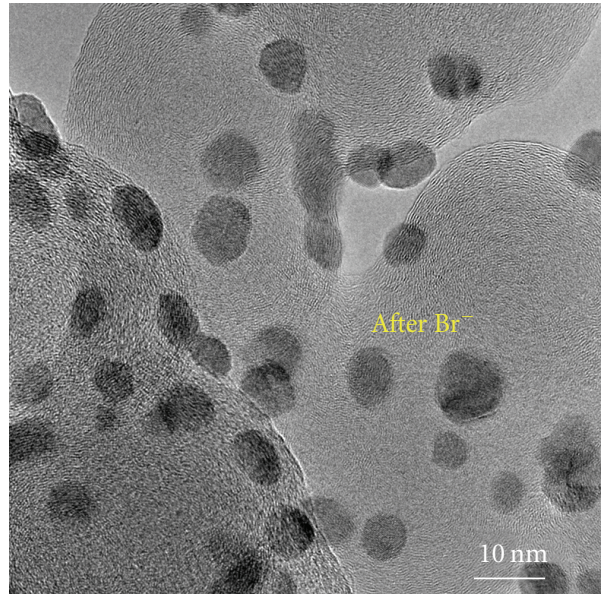

(b)

Figure 6: High-resolution TEM images of the original $\mathrm{Pd}_{3} \mathrm{Co} / \mathrm{C}$ and of $\mathrm{Pt}_{\mathrm{ML}}$ on $\mathrm{Br}$-treated $\mathrm{Pd}_{3} \mathrm{Co} / \mathrm{C}$ [22].

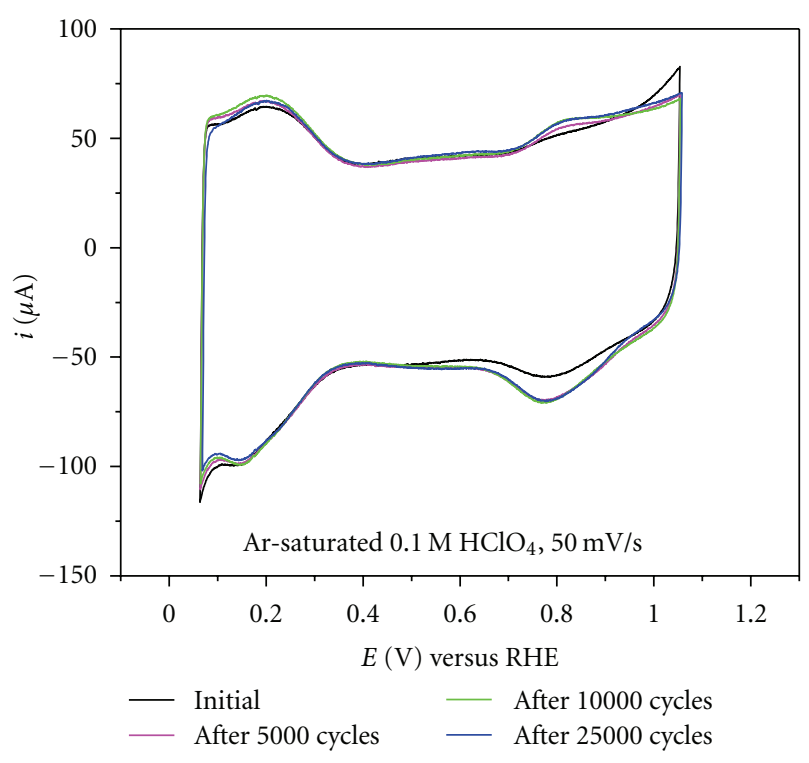

(a)

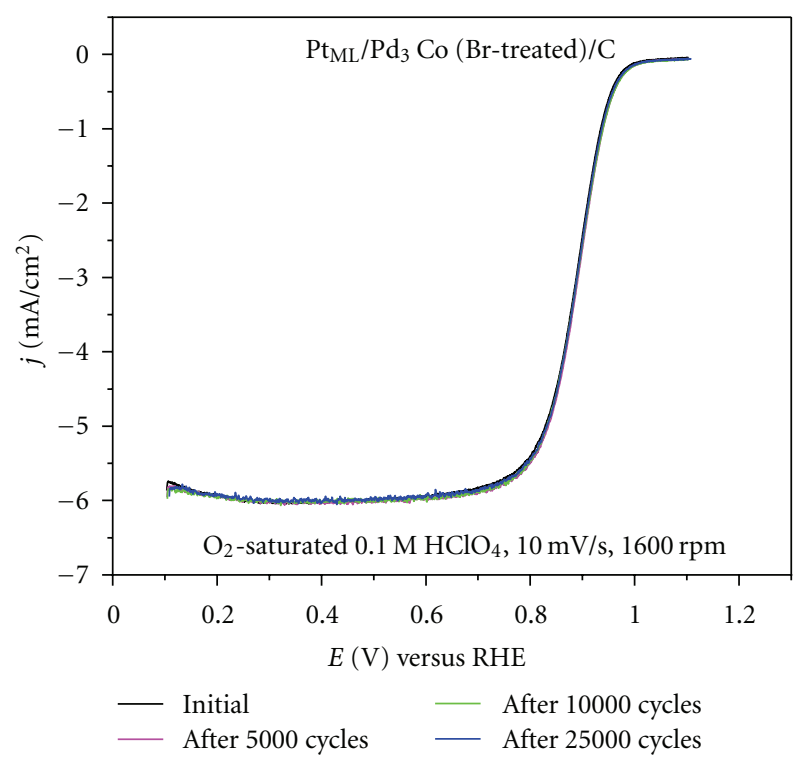

(b)

FIgure 7: Voltammetry curves for the $\mathrm{Pt}_{\mathrm{ML}} / \mathrm{Br}$-treated- $\mathrm{Pd}_{3} \mathrm{Co} / \mathrm{C}(\mathrm{a})$, and polarization curves for the ORR (b) in a stability test involving 25,000 potential cycles [22].

such as iridium or its alloys, to support a Pt monolayer yielding an efficient catalyst. Oxygen binding of Pd, contract to Ir, located in the other side of the volcano plot, is much stronger. Therefore, to reduce the effect of Ir on the dband center of a Pt monolayer, and to assure it can make a moderately strong bond with diatomic oxygen at the surface platinum, we placed a Pd monolayer (interlayer) between the $\mathrm{Pt}$ monolayer and the IrCo core. Thus, while Ir causes the Pt lattice to contract too strongly, and consequently entails low activity, a Pd support entails only a small contraction that suffices to increase the ORR kinetics on platinum.

Figure 8 depicts the voltammetry curves in the absence of $\mathrm{O}_{2}$ for the $\mathrm{Pt}_{\mathrm{ML}} / \mathrm{IrCo}$ with and without a palladium interlayer. The effects of the Pd interlayer on the properties of a Pt monolayer are reflected in the shift of Pt oxidation in comparison with the curve without it. These effects are more pronounced on the ORR kinetics as shown in Figure 9. For both the as-prepared $\mathrm{IrCo}$ and the $\mathrm{Ir}_{3} \mathrm{Co}$ cores, the palladium interlayer engenders a positive shift of about $50 \mathrm{mV}$ and $150 \mathrm{mV}$, respectively, in the half-wave potential compared to the corresponding electrocatalysts lacking a palladium interlayer, clearly demonstrating that this interlayer significantly increases the electrocatalytic activity for the ORR.

For comparison, the mass activities for oxygen reduction at $0.9 \mathrm{~V}$ (RHE) of the $\mathrm{Pt}_{\mathrm{ML}} / \mathrm{IrCo} / \mathrm{C}$ and $\mathrm{Pt}_{\mathrm{ML}} / \mathrm{Pd}_{\mathrm{ML}} / \mathrm{IrCo} / \mathrm{C}$ were calculated and summarized in Figure 10; the activity on commercial $\mathrm{Pt} / \mathrm{C}$ is included as a reference. The $\mathrm{Pt}$ 


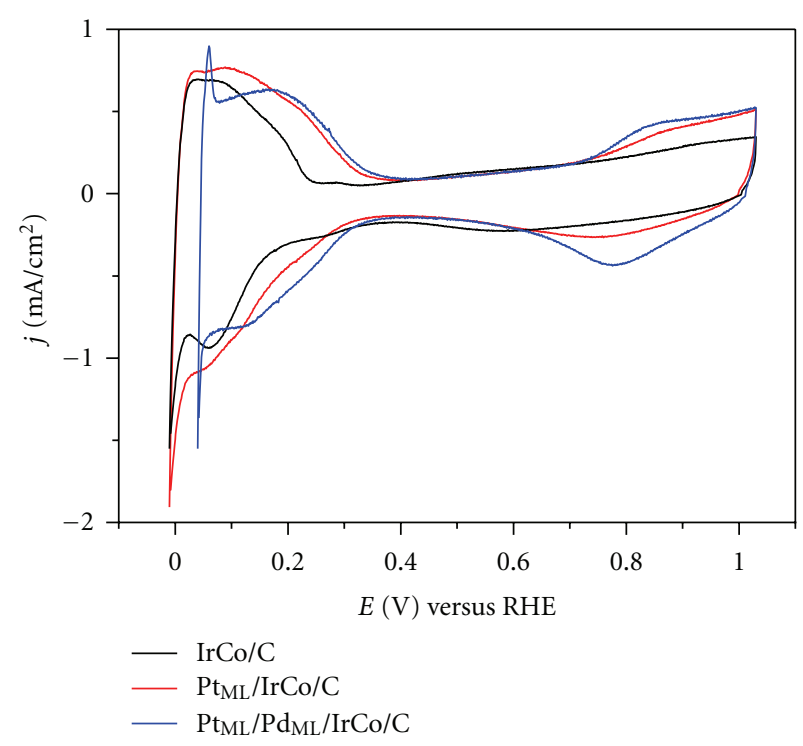

Figure 8: Cyclic voltammograms of $\mathrm{IrCo} / \mathrm{C}$ (black), $\mathrm{Pt} \mathrm{ML}_{\mathrm{ML}} / \mathrm{IrCo} / \mathrm{C}$ (red), and $\mathrm{Pt}_{\mathrm{ML}} / \mathrm{Pd}_{\mathrm{ML}} / \mathrm{IrCo} / \mathrm{C}$ (blue) in argon-blanketed $0.1 \mathrm{M}$ $\mathrm{HClO}_{4}$ at the scan rate of $50 \mathrm{mV} \mathrm{s}^{-1}[28]$.

loadings were calculated from the coulombic charge for the underpotential deposition of copper monolayer. It is exciting to find that the mass activity of the $\mathrm{Pt}_{\mathrm{ML}} / \mathrm{Pd}_{\mathrm{ML}} / \mathrm{IrCo} / \mathrm{C}$ in terms of platinum mass and the platinum-group-metals' mass is, respectively, seven-times and four-times higher than that obtained with $\mathrm{Pt}_{\mathrm{ML}} / \mathrm{IrCo} / \mathrm{C}$ (without palladium interlayer). These substantial enhancements in the specific activities again highlight the essential role of the palladium monolayer in improving the overall kinetics for the ORR.

To further explore these observations, we investigated the ORR activity on these surfaces using density functional theory, within the plane-wave approach, using the program VASP $[33,34]$, with the Perdew-Burke-Ernzerhof exchangecorrelation functional [35] within the generalized gradient approximation. For further analysis and comparison of the relative reactivity of all surfaces at $0.9 \mathrm{~V}$, we constructed an activity measure based on a microkinetic model that is detailed elsewhere [36]. In brief, the maximal activity $A$ can be expressed as $A=k T \min _{i}\left(\log \left(k_{i} / k_{0}\right)\right)$, where $k_{i}$ is the rate constant of each elementary step [36]. The DFT-based activities at 1 bar, $300 \mathrm{~K}$, and $0.9 \mathrm{~V}$ shown in Figure 11 indicate that the ORR activity on all surfaces studied is limited by the $\mathrm{OH}$ removal step. These values closely follow the trend in $\mathrm{OH}$ adsorption; therefore, $\mathrm{OH}$ adsorption energy is a descriptor of ORR activity of these surfaces. Both catalysts, IrCo and Ir3Co, with a Pd interlayer have a weaker $\mathrm{OH}$ binding than those without the interlayer, which is in agreement with the experimental results, that is, higher activity was observed on the catalysts with a $\mathrm{Pd}$ interlayer. Moreover, we note that the effect of the reduced lattice constant of the Ir-Co cores by the Pd interlayer clearly is reflected in the adsorption energies of the adsorbates. Ramírez-Caballero et al. [37] recently reported adsorption energies of $\mathrm{O}$ and $\mathrm{OH}$, respectively, on $\mathrm{Pt} / \mathrm{Pd}$ (bulk) as -4.21 and $-2.33 \mathrm{eV}$; the values of $\mathrm{O}$ and $\mathrm{OH}$, correspondingly, for $\mathrm{Pt} / \mathrm{PdIr}_{3} \mathrm{Co}$ are -3.62 and $-2.47 \mathrm{eV}$, and for $\mathrm{Pt} / \mathrm{Pd} / \mathrm{IrCo}$ are -3.48 and $-2.10 \mathrm{eV}$.

To summarize, this section describes a simple method of improving Pt monolayer core-shell catalysts that have an inadequate Pt-core interaction causing their relatively low ORR activity. Using a Pd monolayer as an interlayer between $\mathrm{Pt}$ and the core modifies their interaction and improves their ORR activity significantly. Employing the IrCo and $\operatorname{Ir}_{3} \mathrm{Co}$ alloy cores as supports, we demonstrated the essential role of a palladium interlayer in developing excellent platinum monolayer electrocatalysts for the ORR. Incorporating a palladium interlayer in the $\mathrm{Pt}_{\mathrm{ML}} / \mathrm{IrCo} / \mathrm{C}$ catalyst realized a sevenfold- and a fourfold-higher specific activity, respectively, in terms of platinum mass and platinum-groupmetals' mass. Our results reveal that the right choice of an interlayer, such as Pd, can facilitate the use of stable and relatively inexpensive core, such as $\mathrm{IrCo}$, and tune the electrocatalytic properties of the surface platinum monolayer to achieve an efficient ORR electrocatalyst. Our DFT calculations corroborated these findings. Therefore, improved, lowcost ORR electrocatalysts with high activity, and increased potential for commercialization, can be obtained based on this approach.

3.2. $P t_{M L} /(P d A u)_{M L} / P d / C$ [38]. The above example evidently demonstrated the meditation effect of the interlayer for the interaction between Pt monolayer and the metal core. The state-of-the-art $\mathrm{Pt}_{\mathrm{ML}} / \mathrm{Pd} / \mathrm{C}$ has been shown to be one of the electrocatalysts that is close to the optimum design for the ORR in terms of the value of oxygen binding energy and the position of d-band center. To further perfect this electrocatalyst, we modified the Pd core by the addition of a $\mathrm{PdAu}$ layer with only a small content of Au included, forming a new substrate for Pt monolayer.

The deposition of the PdAu alloy layer on the $\mathrm{Pd} / \mathrm{C}$ surface was carried out via Cu UPD method. The detail of the structure for this modified $\mathrm{Pt}_{\mathrm{ML}}$ electrocatalyst is illustrated in Figure 12. Three compositions of the PdAu alloy layer were studied, namely, $\mathrm{Pd}_{95} \mathrm{Au}_{5}, \mathrm{Pd}_{90} \mathrm{Au}_{10}$, and $\mathrm{Pd}_{80} \mathrm{Au}_{20}$. Their polarization curves for ORR are displayed in Figure 13. All of the catalysts show improved ORR activities over those without an alloy sublayer. The activities can be ranked in a decreasing order as $\mathrm{Pd}_{90} \mathrm{Au}_{10}>\mathrm{Pd}_{95} \mathrm{Au}_{5}>\mathrm{Pd}_{80} \mathrm{Au}_{20}>\mathrm{Pd}_{100}$, where $\mathrm{Pd}_{100}$ represents the catalyst without an alloy layer. The $\mathrm{Pt}_{\mathrm{ML}}$ catalyst with $10 \mathrm{at} \% \mathrm{Au}$ sublayer exhibits the highest activity.

The enhanced ORR activities can be attributed to the surface strain and the d-band center shift of the $\mathrm{Pt}_{\mathrm{ML}}$ induced by the alloy layer. The lattice constants of $\mathrm{Pt}, \mathrm{Pd}$, and $\mathrm{Au}$ are $3.920,3.890$, and $4.080 \AA$, respectively. The mismatch between Pt and Pd produces a lateral compressive strain when a $\mathrm{Pt}_{\mathrm{ML}}$ is deposited on Pd (extended surfaces): $\varepsilon_{\mathrm{Pt} / \mathrm{Pd}}=\left(\alpha_{\mathrm{Pt}}-\alpha_{\mathrm{Pd}}\right) / \alpha_{\mathrm{Pd}}=0.8 \%$, where $\varepsilon$ is the lateral strain and $\alpha$ is the lattice constant. This is for flat surfaces. For nanoparticles, surface curvature also contributes to producing a strain $[39,40]$. For a $7.8 \mathrm{~nm}$ particle, this 


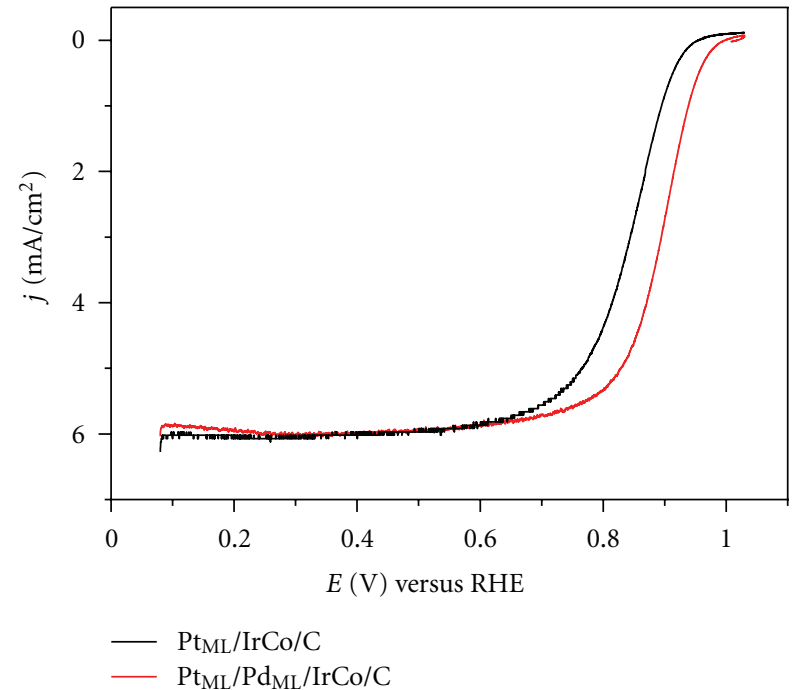

(a)

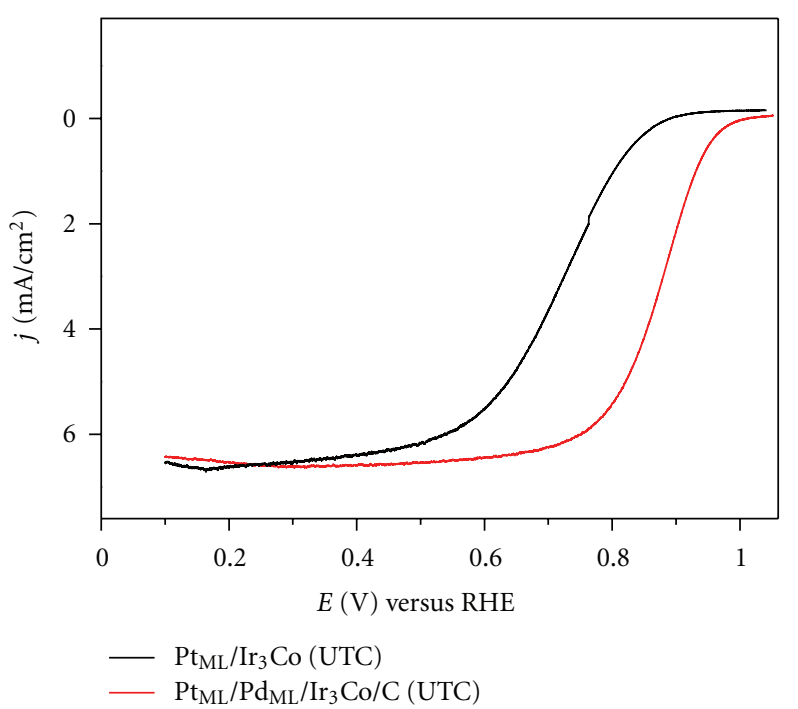

(b)

Figure 9: Polarization curves of $\mathrm{Pt}_{\mathrm{ML}} / \mathrm{IrCo} / \mathrm{C}$ (a) and $\mathrm{Pt}_{\mathrm{ML}} / \mathrm{Ir}_{3} \mathrm{Co} / \mathrm{C}$ (b) with (red curves) and without (black curves) a palladium interlayer in oxygen-saturated $0.1 \mathrm{M} \mathrm{HClO}_{4}$. Scan rate: $10 \mathrm{mV} \mathrm{s}^{-1}$; rotation speed: $1600 \mathrm{rpm} \mathrm{[28].}$

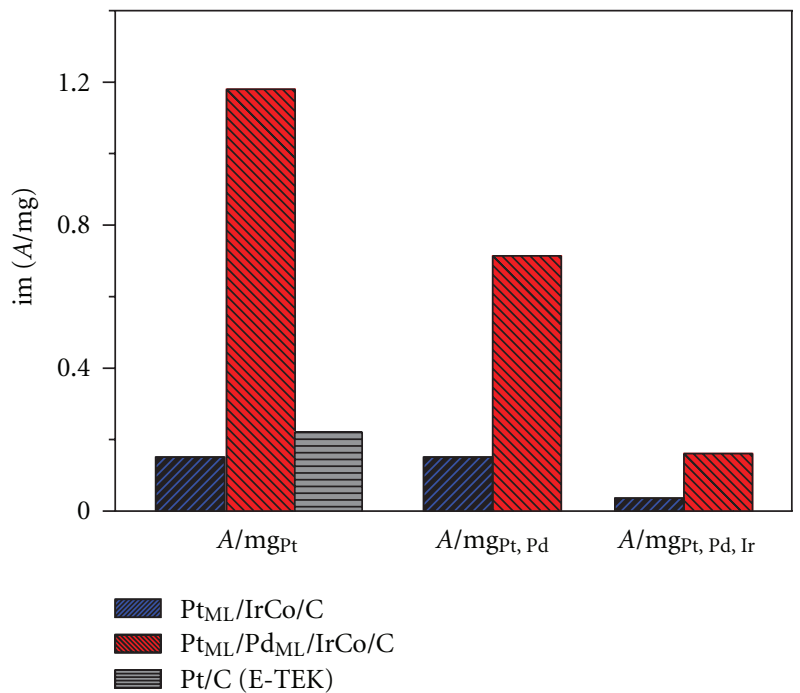

(a)

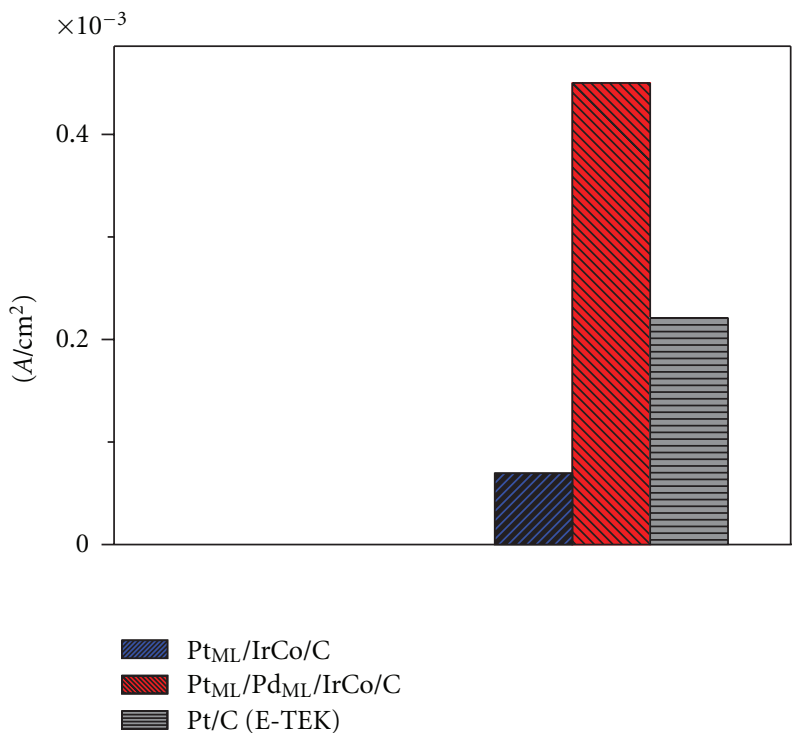

(b)

Figure 10: Comparison of the mass activity in terms of Pt mass, $(\mathrm{Pt}+\mathrm{Pd})$ mass and the platinum-group-metal's mass (a) and the surfacearea activity (b) at $0.9 \mathrm{~V}$ (RHE) of $\mathrm{Pt}_{\mathrm{ML}} / \mathrm{IrCo} / \mathrm{C}$ (blue) and $\mathrm{Pt}_{\mathrm{ML}} / \mathrm{Pd}_{\mathrm{ML}} / \mathrm{IrCo} / \mathrm{C}$ for oxygen reduction. The activity of $\mathrm{Pt} / \mathrm{C}$, the commercial catalyst, is shown in black [28].

contribution is estimated to be about $\sim 0.4 \%$. Although the total surface strain of $\sim 1.2 \%$ is still small, contraction in surface atoms in the radial direction can make a significant contribution. The enhancement in ORR activity due to the lattice contraction has been demonstrated in experiments and density functional theory calculations [18]. Huang et al. [41] have recently reported that up to $8 \%$ reduction in bond length was found in $4 \mathrm{~nm}$ Au nanoparticles.

When a $\mathrm{Pt}_{\mathrm{ML}}$ is deposited on $\mathrm{Au}$, a lateral tensile strain can be generated in $\mathrm{Pt}_{\mathrm{ML}}$ at $3.92 \%$ that will expand $\mathrm{Pt}$ in the surface layer. Contraction due to the decreasing coordination numbers of surface atoms will act in the opposite direction. Therefore, when $\mathrm{Pd}-\mathrm{Au}$ alloys are used as the sublayer for mediation, the interplay of lateral strain (compressive and tensile) and radial contraction (compressive strain) can lead to activity improvement of the ORR catalysts, as observed in the experiments. There should be an optimal alloy composition, that is, both too little and too much $\mathrm{Au}$ would decrease the ORR activity. For the results reported here, the $10 \mathrm{at} \% \mathrm{Au}$, which is estimated using the atomic radii to have about $10.5 \%$ surface coverage by $\mathrm{Au}$ atoms in the alloy sublayer, seems to produce the highest ORR activity. 


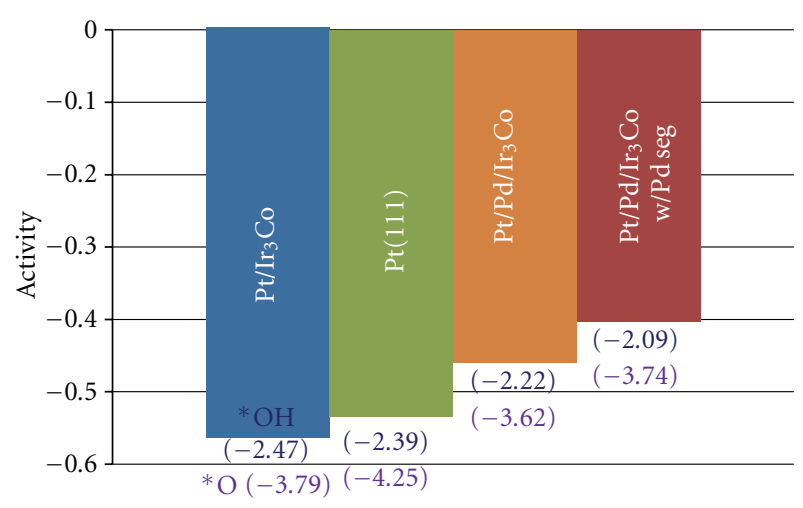

(a)

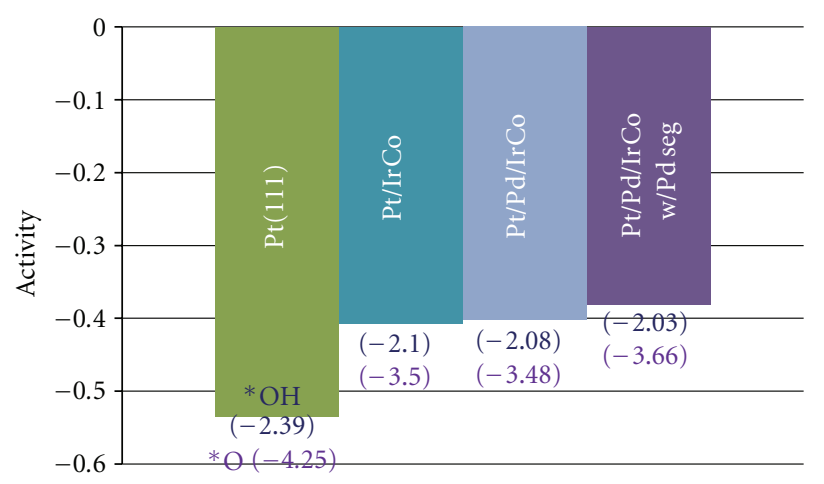

(b)

FIgURE 11: Oxygen reduction activity at $0.9 \mathrm{~V}$ plotted in the order of strongest to weakest $\mathrm{OH}$ binding energy, and the binding energy of $\mathrm{O}$ is also given; both are shown in parenthesis in eV. (a) $\mathrm{Ir}_{3} \mathrm{Co}$, (b) Ir-Co cores. The Pt-skin surfaces with an interlayer of Pd show the highest activities in both cases [28].

While lattice contraction may be important, the interaction of the substrate with $\mathrm{Pt}_{\mathrm{ML}}$ could result in an electronic effect on the ORR activity through charge redistribution [18, 42]. As demonstrated previously, [42] the formation of $\mathrm{PtOH}$ is significantly prohibited for the $\mathrm{Pt}_{\mathrm{ML}}$ on $\mathrm{Pd}$ nanoparticles when compared with Pt nanoparticles. Hydroxyl formation is considered as a major factor affecting ORR activity because of site blockage by $\mathrm{OH}[26]$. Au may play an important role in protecting low-coordination sites on $\mathrm{Pt}$ from being oxidized. Wang et al. [43] recently reported that Au coated with $\mathrm{FePt}_{3}$ stabilizes the oxidation of the surface atoms in certain facets of the nanoparticles. Likewise, the Au in the sublayer of our catalysts also has contributed to the reduction of surface oxidation, leading to the improved ORR activity of the catalysts.

The polarization curves of $\mathrm{Pt}_{\mathrm{ML}} / \mathrm{Pd} / \mathrm{C}$ with a $\mathrm{Pd}_{90} \mathrm{Au}_{10}$ interlayer before and after 5000 potential cycles are shown in Figure 14. Less than $1 \%$ loss in ORR activity was observed, demonstrating the excellent stability of the catalyst. The stabilization of the catalyst can be attributed to the reduction of surface oxidation from $\mathrm{Au}$ in the sublayer, therefore inhibiting the dissolution of metal. The stabilizing effects of $\mathrm{Au}$ on Pt nanoparticles have been reported by Zhang et al.
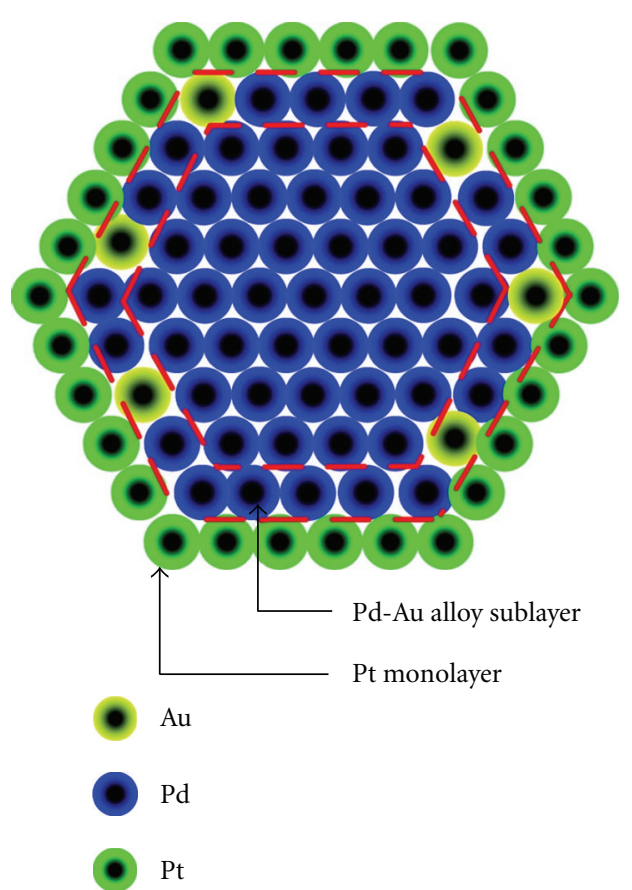

Figure 12: Illustration of the core-shell structure of PdAu alloy sublayer nanoparticles [38].

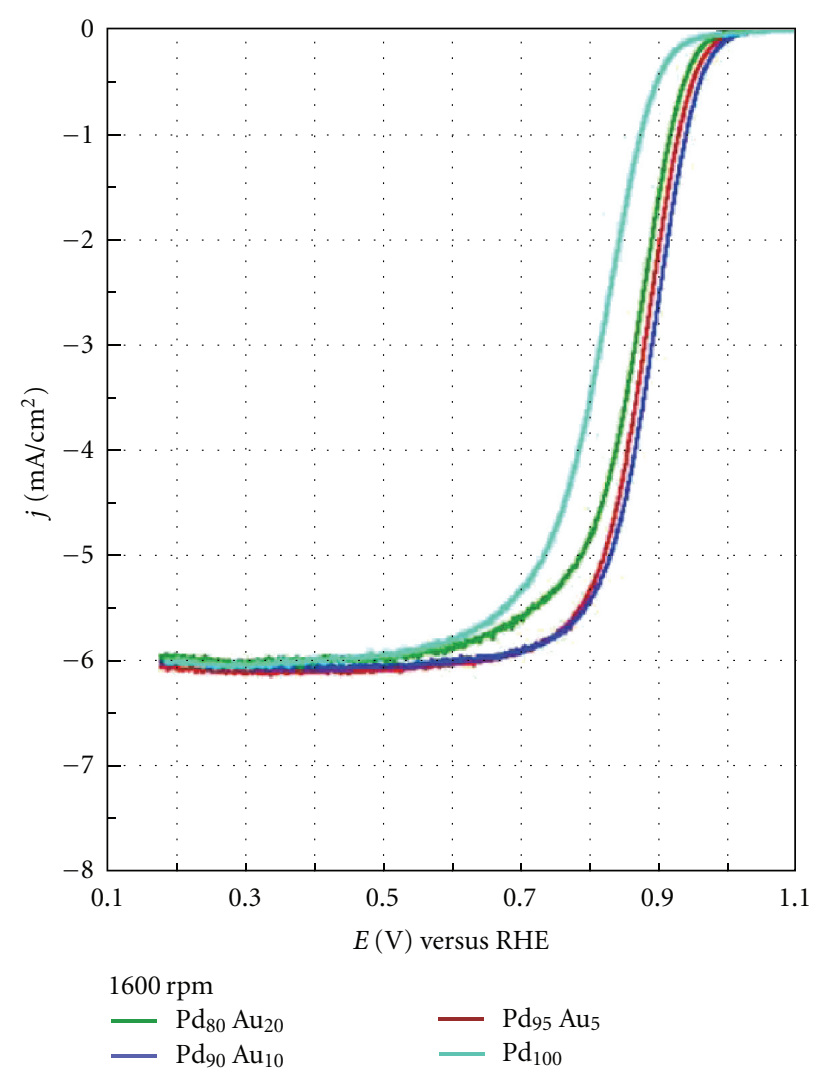

FIGURe 13: ORR activities of $\mathrm{Pt}_{\mathrm{ML}}$ catalysts with different contents of Pd-Au interlayer on a Pd/C core obtained with electrode rotating speed at $1600 \mathrm{rpm}$ in an oxygen-saturated $0.1 \mathrm{M} \mathrm{HClO}_{4}$ [38]. 


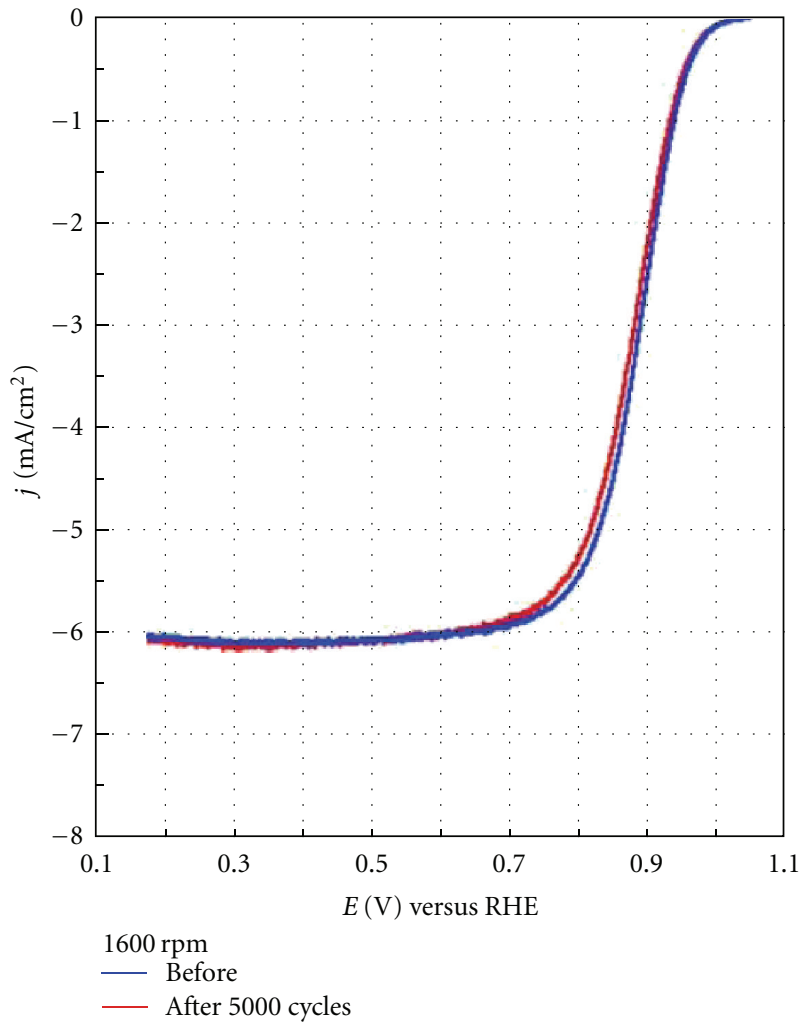

FIgURe 14: Polarization curves for the ORR of the catalyst with $\mathrm{Pd}_{90} \mathrm{Au}_{10}$ alloy sublayer before and after 5000 potential cycles [38].

[44] and other studies [43, 45, 46] have also demonstrated the same effect of $\mathrm{Au}$. The addition of a Pd-Au alloy between $\mathrm{Pt}_{\mathrm{ML}}$ and $\mathrm{Pd} / \mathrm{C}$ core enhance both the activity and stability for ORR from the induced lattice contraction (both lateral and radial). The fact that the sublayer alloy can be of different metals and compositions may open up various opportunities in tailoring catalysts for best ORR activity.

\section{A Core for $\mathrm{Pt}_{\mathrm{ML}}$ with a Segregated Pd Layer on $\mathrm{Pd}_{3} \mathrm{Fe}(111)$ [47]}

Pd-M alloys (M) ( $\mathrm{M}=\mathrm{Co}, \mathrm{Fe}$, or Ti) [19, 48] have shown comparable or even slightly better ORR activity than commercial Pt catalysts. The high ORR kinetics and significantly decreased cost of materials along with their satisfactory stability make some Pd-M alloys very promising candidates to replace conventional $\mathrm{Pt}$ catalysts for the ORR. The enhanced ORR activity observed with bulk and high-surfacearea Pd-M alloys was ascribed either to the modification of the electronic property of Pd on the segregated surface layer $[16,48,49]$ or to the synergistic effect between $\mathrm{Pd}$ and the second metal $[49,50]$. This segregated Pd surface layer that has different electronic properties from pure $\mathrm{Pd}$ [16] was considered to be the key factor responsible for the enhanced ORR activity on Pd-M alloys [51]. Our work on $\mathrm{Pd}_{3} \mathrm{Fe}(111)$ demonstrated that the segregated $\mathrm{Pd}$ layer from high-temperature annealing exhibits the same surface structure but different electronic properties. As shown in

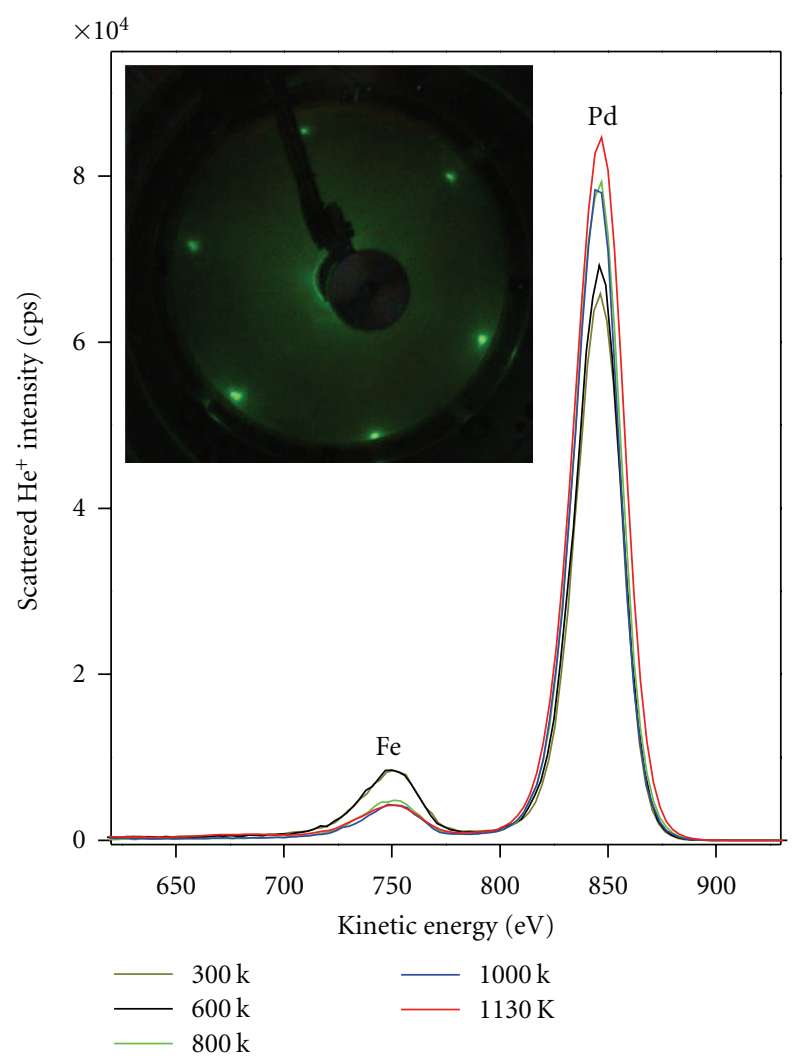

Figure 15: LEIS spectra $\left(1 \mathrm{keV} \mathrm{He}^{+}\right)$for a $\mathrm{Pd}_{3} \mathrm{Fe}(111)$ surface annealed to various temperatures. Inset shows a $(1 \times 1)$ LEED pattern for a $\mathrm{Pd}_{3} \mathrm{Fe}(111)$ surface annealed to $1200 \mathrm{~K}$. The electron beam energy was $55 \mathrm{eV}$ [47].

Figure 15 upon annealing to $1200 \mathrm{~K}$, surface Pd signal increases and a sharp $(1 \times 1)$ LEED pattern was observed, suggesting that Pd segregates to the surface and forms a well-ordered layer. This segregated Pd layer modified the interaction of $\mathrm{Pt}_{\mathrm{ML}}$ and its substrate, and an enhancement of the ORR activity was observed.

When the annealed $\mathrm{Pd}_{3} \mathrm{Fe}(111)$ electrode was treated with $0.1 \mathrm{M} \mathrm{HClO}_{4}$, only a small amount, if any, of Fe in the topmost layer immediately dissolved since no voltammetric features related to $\mathrm{Fe}$ dissolution were observed, leaving a pure Pd skin-like layer on the surface (referred to hereafter as $\mathrm{Pd} /$ annealed- $\left.\mathrm{Pd}_{3} \mathrm{Fe}(111)\right)$ and verifying the migration of $\mathrm{Pd}$ to the surface during annealing.

Figure 16(a) shows the cyclic voltammetry scans for a $\mathrm{Pd} /$ annealed- $\mathrm{Pd}_{3} \mathrm{Fe}(111)$ surface immersed in $0.1 \mathrm{M} \mathrm{HClO}_{4}$ at $0.05 \mathrm{~V}$ and subsequently cycled between $0.05 \mathrm{~V}$ and various positive potential limits at a scan rate of $20 \mathrm{mV} \mathrm{s}^{-1}$. A reversible process is observed between +0.05 and $+0.40 \mathrm{~V}$, a finding that has not been observed on a $\mathrm{Pd}(111)$ electrode (Figure 16(b)) [52, 53]. Baldauf and Kolb [54] reported that $H$ absorption $\left(H_{\mathrm{abs}}\right)$ occurs only for Pd films thicker than $2 \mathrm{ML}$. This reversible process that is very similar to the $H_{\mathrm{ads}}$ /des occurred on a $\mathrm{Pd}_{\mathrm{ML}} / \mathrm{Pt}(111)$ electrode [55] and therefore is tentatively assigned to $H_{\mathrm{ads}}$ /des on a segregated $\mathrm{Pd}$ layer on $\mathrm{Pd}_{3} \mathrm{Fe}(111)$ surface. The surface oxidation of 


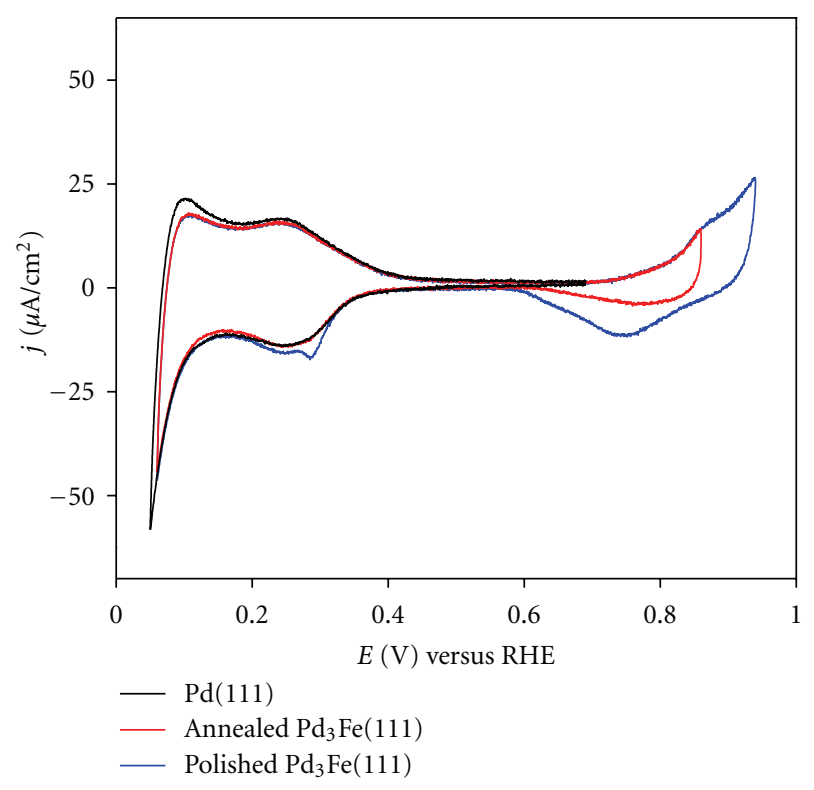

(a)

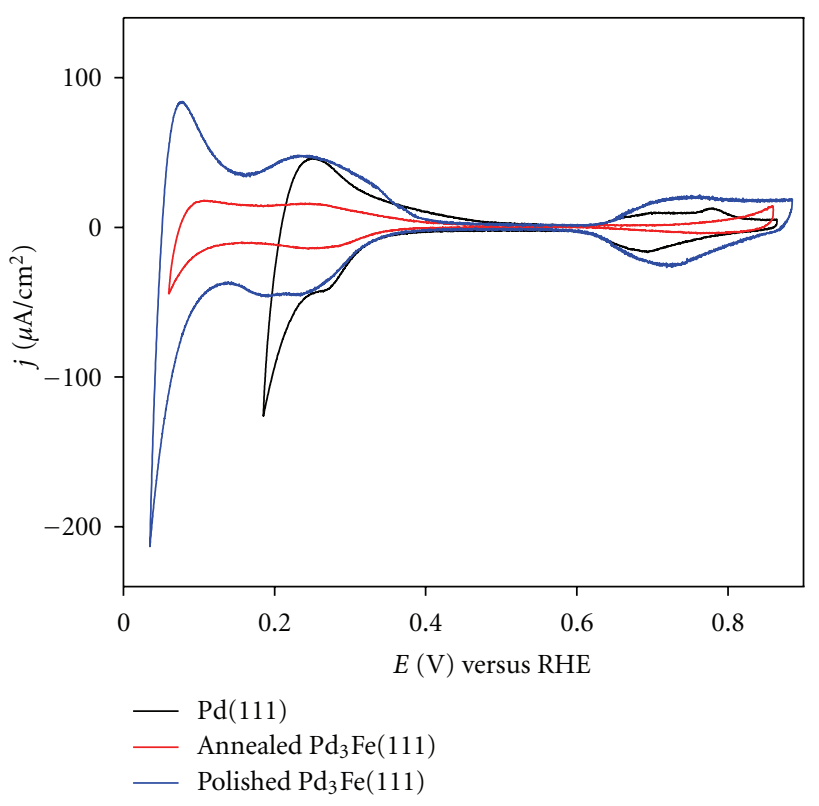

(b)

Figure 16: (a) Voltammetry curves for an annealed $\mathrm{Pd}_{3} \mathrm{Fe}(111)$ in $0.1 \mathrm{M} \mathrm{HClO}_{4}$ solution with different positive potential windows. (b) Voltammetry curves for an annealed (red line) and a polished $\mathrm{Pd}_{3} \mathrm{Fe}(111)$ (blue line), and $\mathrm{Pd}(111)$ (black line) in $0.1 \mathrm{M} \mathrm{HClO}_{4}$ solution. Scan rate: $20 \mathrm{mV} \mathrm{s}^{-1}[47]$.

a $\mathrm{Pd} /$ annealed- $\mathrm{Pd}{ }_{3} \mathrm{Fe}(111)$ electrode does not occur until the positive potential limit extends beyond $0.73 \mathrm{~V}$ (red and blue line in Figure 16(a)); this indicates the positively shifted onset of oxidation of $\sim 0.1 \mathrm{~V}$ relative to that of $\mathrm{Pd}(111)$. The charge density under the cathodic peak at $\sim 0.73 \mathrm{~V}$, reflecting the surface coverage of oxygen-containing species, is considerably smaller for the $\mathrm{Pd} /$ annealed- $\mathrm{Pd}_{3} \mathrm{Fe}(111)$ electrode than for the $\operatorname{Pd}(111)$ one (Figure 16(b)). These important new properties of the alloy's surface play a role in determining the kinetics of the ORR. A similar electrochemical phenomenon occurred on a $\mathrm{Pt}$ skin surface on $\mathrm{Pt}_{3} \mathrm{Ni}$ alloys [56]. The voltammetry curves stayed unchanged, even after driving the positive potential limit very high (i.e., $0.95 \mathrm{~V}$ ).

To assess the role of Fe in determining the electrochemical and catalytic properties of the $\mathrm{Pd}$ layer on the $\mathrm{Pd}_{3} \mathrm{Fe}(111)$ surface, the Fe atoms in several topmost layers were removed almost completely by polishing and exposing such surface to acid. The remaining Pd layers on the $\mathrm{Pd}_{3} \mathrm{Fe}(111)$ electrode have some similarity to the $\mathrm{Pt}_{3} \mathrm{Ni}$ skeleton surface described by Stamenkovic et al. [57] except this pure Pd surface layer likely was thicker. This electrode showed very similar electrochemical behavior to that of a $\operatorname{Pd}(111)$ electrode, which verifies the role of Fe in this catalyst.

Figure 17(a) provides a set of polarization curves for the ORR on the $\mathrm{Pt}_{\mathrm{ML}}$-covered surfaces of $\mathrm{Pd} /$ annealed$\mathrm{Pd}_{3} \mathrm{Fe}(111)$ and $\mathrm{Pd}(111)$, and $\mathrm{Pt}(111)$ obtained in $0.1 \mathrm{M}$ $\mathrm{HClO}_{4}$ at room temperature. Figure 17(b) shows their corresponding specific activities at $0.9 \mathrm{~V}$. A Pt monolayer supported on $\mathrm{Pd} /$ annealed- $\mathrm{Pd}_{3} \mathrm{Fe}(111)$ shows the highest ORR kinetics among these three surfaces, by a factor of at least 2 compared with that of the $\operatorname{Pt}(111)$ surface, and
TABle 1: Binding energies of $\mathrm{OH}$ on the surfaces of $\mathrm{Pt}(111)$, $\mathrm{Pt}_{\mathrm{ML}} / \mathrm{Pd}(111)$ and $\mathrm{Pt}_{\mathrm{ML}} / \mathrm{Pd} / \mathrm{Pd}_{3} \mathrm{Fe}(111)$.

\begin{tabular}{llll}
\hline & $\mathrm{Pt}(111)$ & $\mathrm{Pt}_{\mathrm{ML}} / \mathrm{Pd}(111)$ & $\mathrm{Pt}_{\mathrm{ML}} / \mathrm{Pd} / \mathrm{Pd}_{3} \mathrm{Fe}(111)$ \\
\hline $\mathrm{BE}_{\mathrm{OH}}(\mathrm{eV})$ & -2.09 & -2.07 & -1.93 \\
\hline
\end{tabular}

Data from [46].

also demonstrates significantly increased ORR activity in comparison with that of the $\mathrm{Pt}_{\mathrm{ML}} / \mathrm{Pd}(111)$ surface.

To elucidate the fundamental aspects of the ORR activity of composite core-shell structures, DFT calculations were conducted for model systems composed of a single $\mathrm{Pt}_{\mathrm{ML}}$ on a Pd monolayer supported on the close-packed surfaces of several different substrates. On the basis of this analysis, the binding energy of $\mathrm{OH}$ on $\mathrm{Pt}_{\mathrm{ML}} / \mathrm{Pd}(111)$ is weaker than that of $\mathrm{OH}$ on $\mathrm{Pt}(111)$ and $\mathrm{OH}$ removal is easier on $\mathrm{Pt}_{\mathrm{ML}} / \mathrm{Pd}(111)$ than it is on $\mathrm{Pt}(111)$ (Table 1). As a result, the ORR activity is increased on $\mathrm{Pt}_{\mathrm{ML}} / \mathrm{Pd}(111)$ compared to that on $\mathrm{Pt}(111)$.

As shown in Table $1, \mathrm{Pt}_{\mathrm{ML}} / \mathrm{Pd} / \mathrm{Pd}_{3} \mathrm{Fe}(111)$, an appropriate model for the $\mathrm{Pt}_{\mathrm{ML}}$ on the annealed- $\mathrm{Pd}_{3} \mathrm{Fe}(111)$ surface, the binding of $\mathrm{OH}$ on which is destabilized much more than on the $\mathrm{Pt}_{\mathrm{ML}} / \mathrm{Pd}(111)$ and $\mathrm{Pt}(111)$. This leads to $\mathrm{Pt}_{\mathrm{ML}} / \mathrm{Pd} / \mathrm{Pd}_{3} \mathrm{Fe}(111)$ having more $\mathrm{OH}$-free sites for $\mathrm{O}_{2}$ adsorption and reactions than the $\mathrm{Pt}_{\mathrm{ML}} / \mathrm{Pd}(111)$ and $\mathrm{Pt}(111)$ surfaces. Interestingly, we are finding that the activity of $\mathrm{Pt}_{\mathrm{ML}} / \mathrm{Pd}(111)$ and $\mathrm{Pt}(111)$ is limited by $\mathrm{OH}$ removal (left side of the ORR activity volcano plotted against $\mathrm{BE}_{\mathrm{OH}}$ ) whereas the activity of $\mathrm{Pt}_{\mathrm{ML}} / \mathrm{Pd} / \mathrm{Pd}_{3} \mathrm{Fe}(111)$ is limited by the $\mathrm{O}-\mathrm{O}$ bond scission in the $\mathrm{OOH}$ intermediate, placing this surface on the other side of the volcano plot. Yet, a 


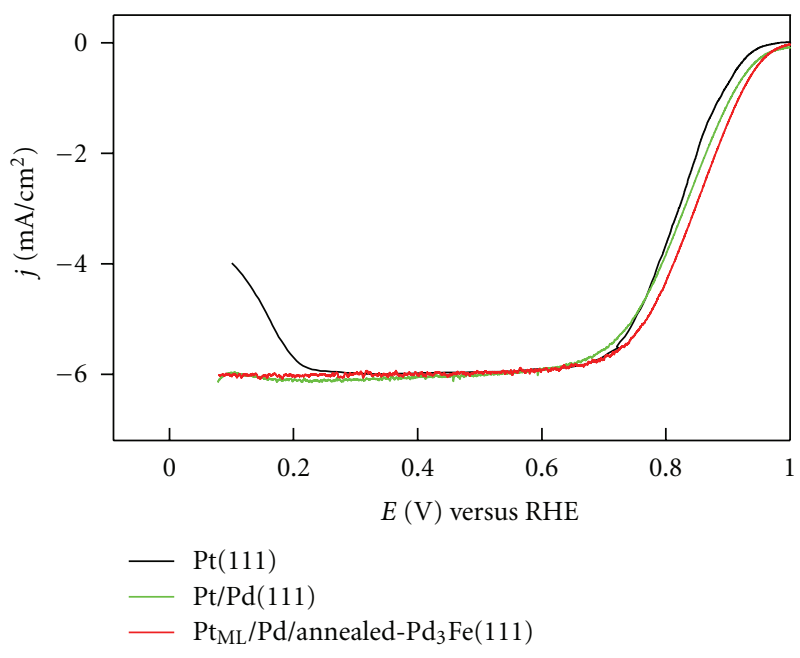

(a)

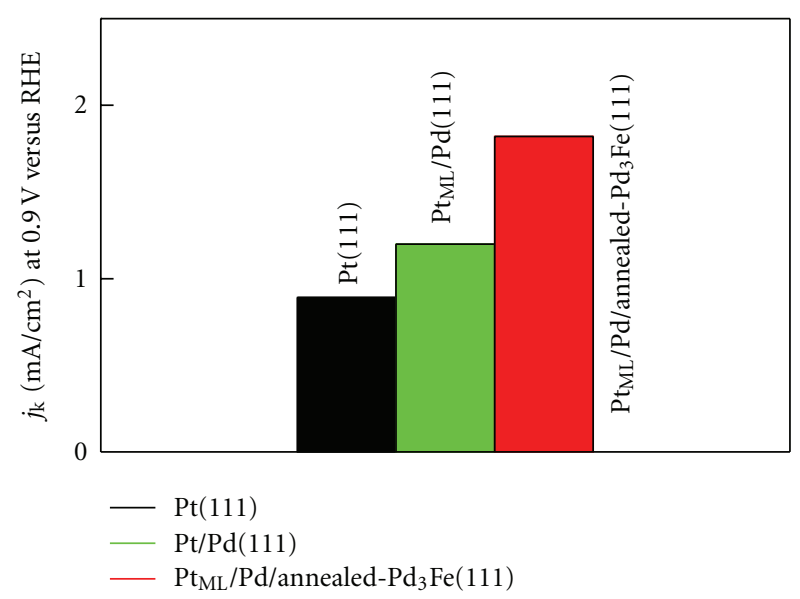

(b)

Figure 17: (a) Polarization curves for the ORR on a Pt monolayer covered annealed-Pd $3 \mathrm{Fe}(111)$ (red), annealed-Pd(111) (green), and $\mathrm{Pt}(111)$ surfaces (black) at $1600 \mathrm{rpm}$ in oxygen-saturated $0.1 \mathrm{M} \mathrm{HClO}_{4}$ at room temperature; scan rate: $20 \mathrm{mV} \mathrm{s}^{-1}$. (b) The bar plot for the comparison of ORR-specific activities of the corresponding three surfaces at $0.9 \mathrm{~V}$ (RHE) [47].

direct comparison between the $\mathrm{BE}_{\mathrm{OH}}$ and the calculated $\mathrm{ORR}$ activities on $\mathrm{Pt}_{\mathrm{ML}} / \mathrm{Pd}(111)$ and $\mathrm{Pt}_{\mathrm{ML}} / \mathrm{Pd} / \mathrm{Pd}_{3} \mathrm{Fe}(111)$ at the relevant bias voltage suggests that the enhanced activity of the latter surface originates mainly from the destabilization of $\mathrm{OH}$ on that surface, compared to that on the former surface.

The segregated $\mathrm{Pd}$ layer further weakens the $\mathrm{Pt}-\mathrm{OH}$ bonding, and is proven to be an excellent substrate for a $\mathrm{Pt}$ monolayer for the ORR, as indicated by the enhanced ORR kinetics on $\mathrm{Pt}_{\mathrm{ML}} / \mathrm{Pd} /$ annealed- $\mathrm{Pd}_{3} \mathrm{Fe}(111)$ compared to that of $\mathrm{Pt}_{\mathrm{ML}} / \mathrm{Pd}(111)$ and $\mathrm{Pt}(111)$.

\section{Subsurface Modification of the Core: Introduction of Iridium to the Pd Subsurface [58]}

This approach introduces a second metal to the subsurface of Pd core and thus generates a Pd-interlayer which alters both the electronic and geometric properties of the core and also affects the catalytic activity of the Pt monolayer.

The purpose of submerging Ir under the Pd surface is to influence the Pt-Pd interaction in order to improve the ORR activity of the already established highly active $\mathrm{Pt}_{\mathrm{ML}} \mathrm{Pd} / \mathrm{C}$ [42]. Also, since Ir has a much higher dissolution potential than Pd (1.16 V for Ir and 0.99 V for Pd), [29] the addition of subsurface Ir can enhance Pd stability under fuel cell operating conditions.

Figure 18 depicts the process of introducing Ir to the subsurface of Pd core for Pt monolayer. In brief, an Ir layer was first placed on $\mathrm{Pd} / \mathrm{C}$ via the $\mathrm{Cu}$ UPD method and then was subsequently annealed at elevated temperatures to enable a thin layer of Pd to segregate to the surface. After that, a Pt monolayer was deposited via the Cu UPD. The Ir loading in $\mathrm{IrPd} / \mathrm{C}$ is estimated to be $4.1 \mathrm{wt} \%$ and there is $11 \mathrm{at} \%$ of $\mathrm{Ir}$ in IrPd.
In Figure 19(a), the voltammetry curve of $\mathrm{Pt}_{\mathrm{ML}} \mathrm{PdIr} / \mathrm{C}$ (red line) is compared to $\mathrm{Pt}_{\mathrm{ML}} \mathrm{Pd} / \mathrm{C}$ (blue line) and $\mathrm{Pt} / \mathrm{C}$ (black line) in de-aerated $0.1 \mathrm{M} \mathrm{HClO}_{4}$ while Figure 19(b) illustrates a set of polarization curves for the ORR on the same samples with the addition of the notannealed sample $\left(\mathrm{Pt}_{\mathrm{ML}} / \mathrm{IrPd} / \mathrm{C}\right.$, green line) at $1,600 \mathrm{rpm}$ in oxygenated $0.1 \mathrm{M}$ $\mathrm{HClO}_{4}$. From the above CVs, the segregated Pd surface layer on PdIr nanoparticles exhibits different electrochemical behavior compared to that of $\mathrm{Pd} / \mathrm{C}$ electrodes. The influence of $\mathrm{Ir}$ is revealed in the oxidation region. The oxidation of $\mathrm{Pt}_{\mathrm{ML}}$ on $\mathrm{PdIr} / \mathrm{C}$ is delayed compared to that of $\mathrm{Pt}_{\mathrm{ML}} / \mathrm{Pd} / \mathrm{C}$ and $\mathrm{Pt} / \mathrm{C}$. This is in qualitative agreement with DFT calculations predicting weaker $\mathrm{Pd}-\mathrm{O}$ interaction on $\mathrm{Pd} / \operatorname{Ir}(111)$ than on $\operatorname{Pd}(111)$ [19].

As shown in Figure 19(b) the $\mathrm{Pt}_{\mathrm{ML}} \mathrm{PdI} / \mathrm{C}$ has higher ORR activity than $\mathrm{Pt} / \mathrm{C}$ and $\mathrm{Pt}_{\mathrm{ML}} \mathrm{Pd} / \mathrm{C}$ even though it has a smaller surface area. The Pt-specific activity (a) and Ptmass activity (b) at $0.9 \mathrm{~V}$ of $\mathrm{Pt} / \mathrm{C}, \mathrm{Pt}_{\mathrm{ML}} \mathrm{Pd} / \mathrm{C}$, and $\mathrm{Pt}_{\mathrm{ML}} \mathrm{PdIr} / \mathrm{C}$ are summarized in Figure 20. The Pt-specific activity for $\mathrm{Pt}_{\mathrm{ML}} \mathrm{PdIr} / \mathrm{C}$ is three-times and $25 \%$ higher than that of $\mathrm{Pt} / \mathrm{C}$ and $\mathrm{Pt}_{\mathrm{ML}} \mathrm{Pd} / \mathrm{C}$, respectively; the Pt-mass activity of $\mathrm{Pt}_{\mathrm{ML}} \mathrm{PdIr} / \mathrm{C}$ is more than 20-times and 25\% higher than that of $\mathrm{Pt} / \mathrm{C}$ and $\mathrm{Pt}_{\mathrm{ML}} \mathrm{Pd} / \mathrm{C}$, respectively.

The influence of the Ir sublayer on the ORR activity could be explained by the position of the $\mathrm{Pt}_{\mathrm{ML}} \mathrm{d}$-band center $\left(\varepsilon_{\mathrm{d}}\right)$. Previous DFT calculations have shown that the $\varepsilon_{\mathrm{d}}$ of the metal monolayer under compressive strain tends to downshift in energy whereas tensile strain has the opposite effect $[6,15]$. A surface characterized by a higherlying $\varepsilon_{\mathrm{d}}$ tends to bind adsorbates more strongly, thereby enhancing the kinetics of dissociation reactions producing these adsorbates. On the other hand, a surface with a lowerlying $\varepsilon_{\mathrm{d}}$ tends to bind adsorbates more weakly and facilitates the formation of bonds towards larger intermediates. The 


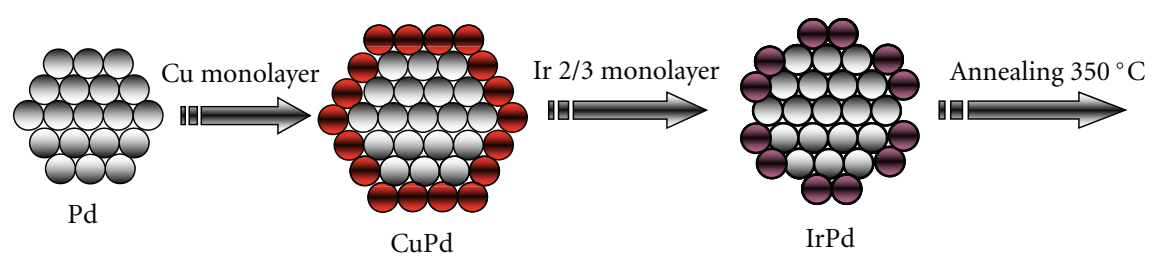

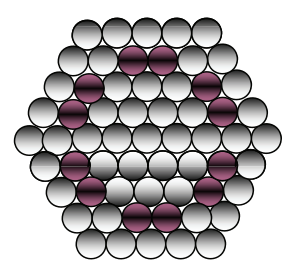

PdIr

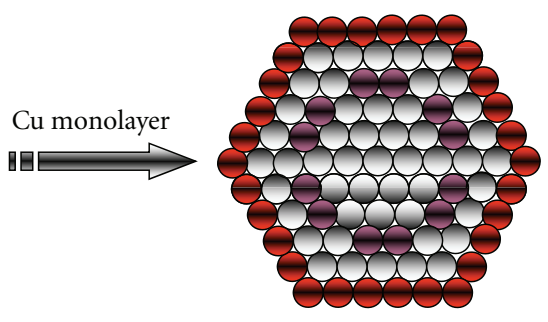

CuPdIr

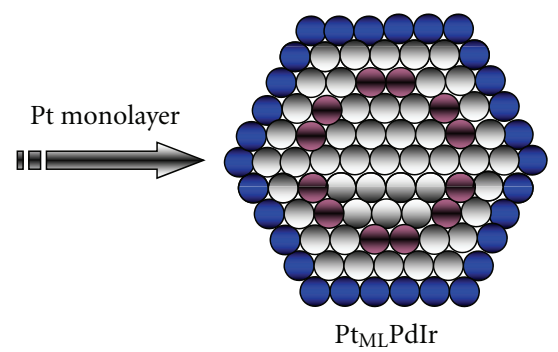

Palladium

Copper

Iridium

Platinum

FIGURE 18: Depiction showing the catalyst preparation (see text) [58].

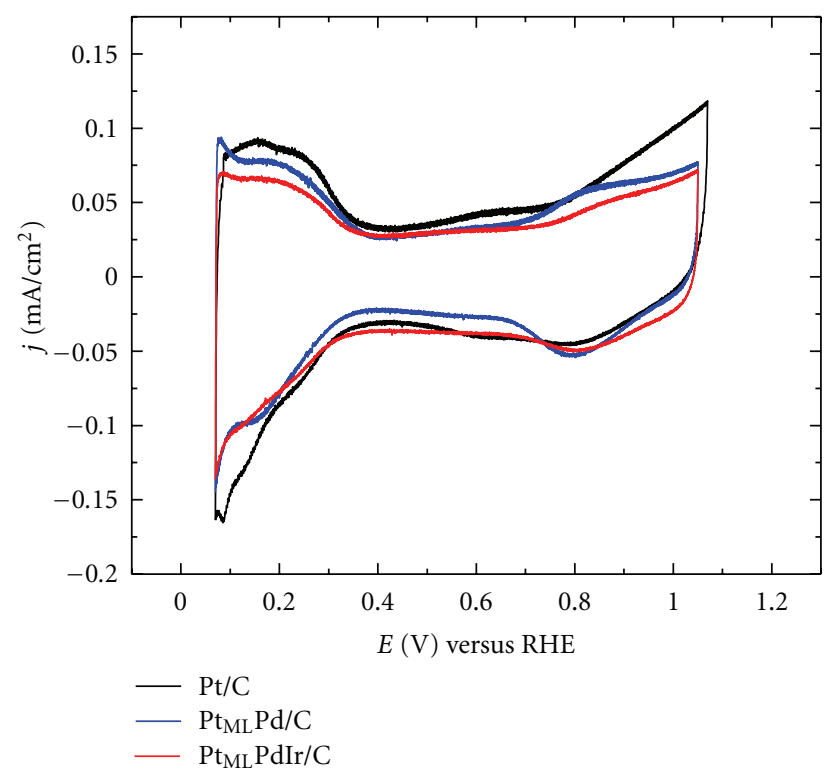

(a)

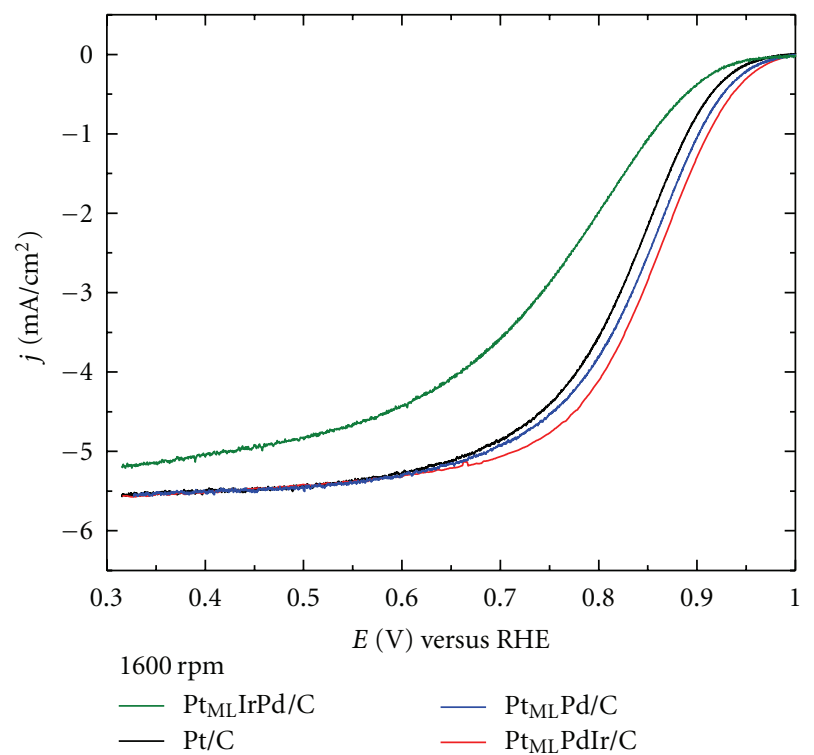

(b)

Figure 19: Voltammetry curves for $\mathrm{Pt}_{\mathrm{ML}} \mathrm{Pd} / \mathrm{C}$ (blue), $\mathrm{Pt}_{\mathrm{ML}} \mathrm{PdIr} / \mathrm{C}$ (red), and $\mathrm{Pt} / \mathrm{C}$ (black) in deaerated $0.1 \mathrm{M} \mathrm{HClO}_{4}$ solution. Scan rate, $20 \mathrm{mVs}^{-1}$. (b) Polarization curves for the ORR on $\mathrm{Pt}_{\mathrm{ML}} \mathrm{IrPd} / \mathrm{C}$ (green), $\mathrm{Pt}_{\mathrm{ML}} \mathrm{Pd} / \mathrm{C}$ (blue), $\mathrm{Pt}_{\mathrm{ML}} \mathrm{PdIr} / \mathrm{C}$ (red), and $\mathrm{Pt} / \mathrm{C}$ (black) at 1,600 rpm in oxygen-saturated $0.1 \mathrm{M} \mathrm{HClO}_{4}$ solution. Scan rate, $10 \mathrm{mVs}^{-1}$ [58].

$\mathrm{Pt}_{\mathrm{ML}}$ on $\mathrm{Pd}$ is compressed but the position of the $\varepsilon_{\mathrm{d}}$ for the $\mathrm{Pt}_{\mathrm{ML}}$ depends both on the strain (geometric effects) and on the electronic interaction between the $\mathrm{Pt}_{\mathrm{ML}}$ and its substrate (ligand effect) [6]. Introducing subsurface Ir causes a small contraction of the Pd surface layer due to the smaller atomic size of Ir compared to $\mathrm{Pd}$. As a consequence, the $\mathrm{Pt}_{\mathrm{ML}}$ put on top of the Pd surface covering the PdIr subsurface will be further compressed causing additional downshift in $\varepsilon_{\mathrm{d}}$ which is manifested by weaker $\mathrm{Pt}-\mathrm{OH}$ interaction leading to the reduced oxidation of this ternary system. Since the intrinsic 


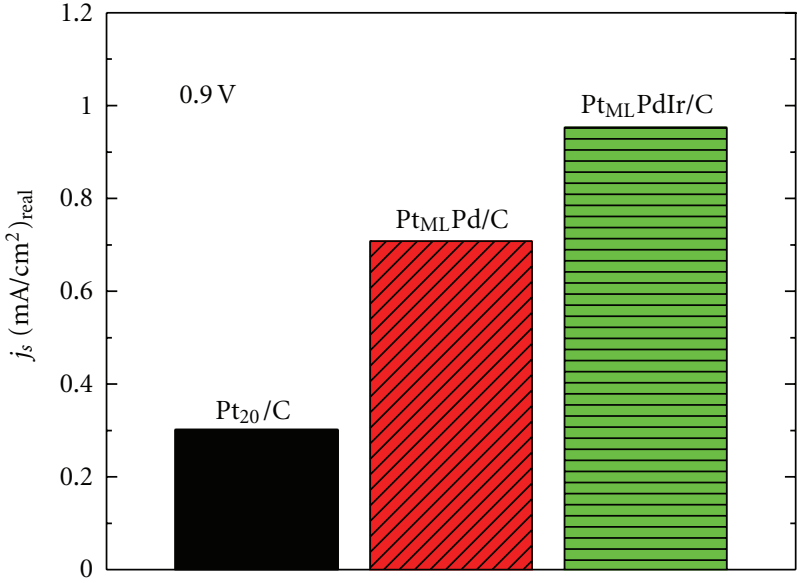

(a)

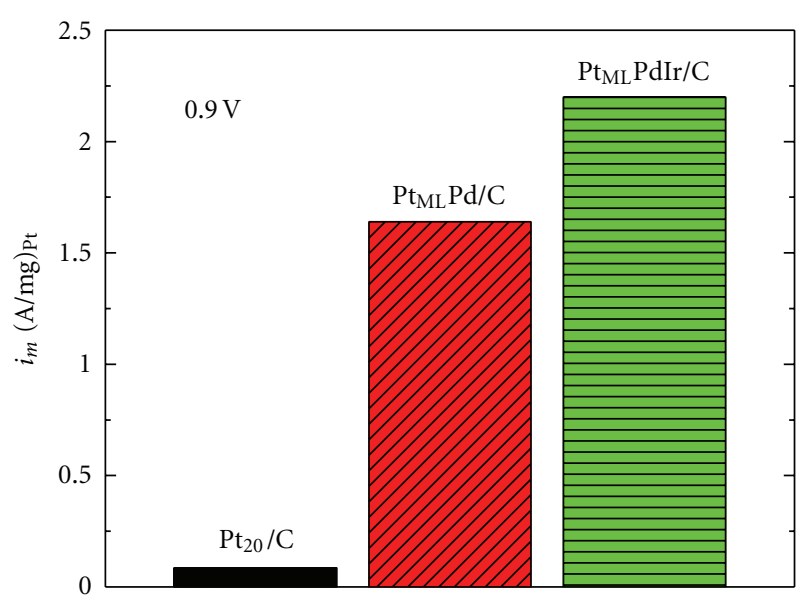

(b)

FIgure 20: (a) Pt-surface specific activity, (b) Pt-mass activities of $\mathrm{Pt} / \mathrm{C}, \mathrm{Pt}_{\mathrm{ML}} \mathrm{Pd} / \mathrm{C}$, and $\mathrm{Pt}_{\mathrm{ML}} \mathrm{PdIr} / \mathrm{C}$ at $0.9 \mathrm{~V}$ versus $\mathrm{RHE}$ [58].

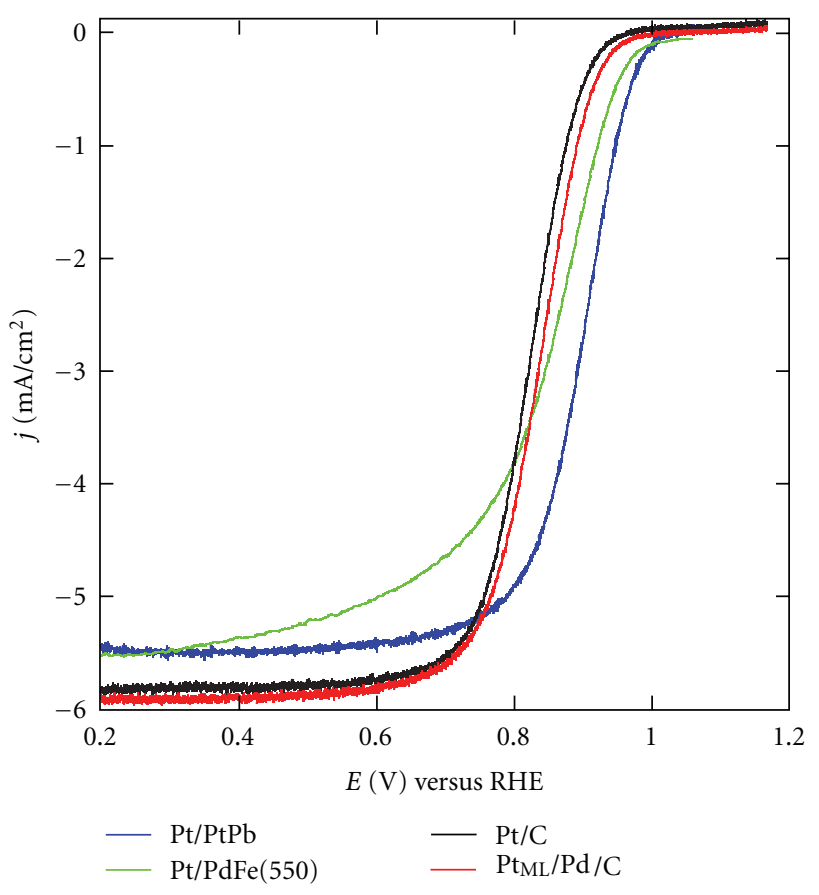

FIgure 21: Comparison of the activities for the ORR of $\mathrm{Pt} / \mathrm{C}$, core-shell $\mathrm{Pt}_{\mathrm{ML}} / \mathrm{Pd} / \mathrm{C}$, and $\mathrm{Pt} / \mathrm{PtPb}$ and $\mathrm{Pt} / \mathrm{PdFe}$ in $0.1 \mathrm{M} \mathrm{HClO}_{4}$; $1600 \mathrm{rpm} ; 10 \mathrm{mV} / \mathrm{s}[59]$.

ORR activity is largely determined by the binding energy of $\mathrm{OH}$, weaker $\mathrm{Pt}-\mathrm{OH}$ interaction should result in enhanced ORR activity.

To directly demonstrate the destabilization of $\mathrm{OH}$ on $\mathrm{Pt}_{\mathrm{ML}} \mathrm{PdIr}$ (as compared to $\mathrm{Pt}_{\mathrm{ML}} \mathrm{Pd}$ or $\mathrm{Pt}$ ), density functional theory calculations were performed on representative close packed (111) facets of the appropriate model systems. The results of these calculations are shown in Table 2. The calculations show that depositing a monolayer of $\mathrm{Pt}$ on a $\mathrm{Pd}$ substrate destabilizes $\mathrm{OH}$ binding $\left(\mathrm{BE}_{\mathrm{OH}}=-2.07 \mathrm{eV}\right)$ as compared to pure $\mathrm{Pt}\left(\mathrm{BE}_{\mathrm{OH}}=-2.17 \mathrm{eV}\right)$ or $\mathrm{Pd}\left(\mathrm{BE}_{\mathrm{OH}}=\right.$
$-2.29 \mathrm{eV})$. Since the lattice constant for $\mathrm{Pt}$ and $\mathrm{Pd}$ are quite similar, this difference is mostly a manifestation of the ligand effect. Introducing Ir into the second sublayer below a $\mathrm{Pt}_{\mathrm{ML}}$ and a $\mathrm{Pd}_{\mathrm{ML}}$ sublayer further reduces binding of $\mathrm{OH}$ on the $\mathrm{Pt}$ surface $\left(\mathrm{BE}_{\mathrm{OH}}=-2.00 \mathrm{eV}\right)$. In the case that the catalysts were not annealed prior to depositing the $\mathrm{Pt}$ overlayer, $\mathrm{OH}$ binding is enhanced $\left(\mathrm{BE}_{\mathrm{OH}}=-2.21 \mathrm{eV}\right)$, translating into ORR performance of the notannealed $\mathrm{Pt}_{\mathrm{ML}} / \mathrm{IrPd}$ inferior to that of pure $\mathrm{Pt}$, as one can see in Figure 20(b). Therefore, according to our calculations, the annealed $\mathrm{Pt}_{\mathrm{ML}} / \mathrm{PdIr}$ catalyst possesses the weakest binding of $\mathrm{OH}$ of all systems studied here. Weaker binding of $\mathrm{OH}$ leads to lower $\mathrm{OH}$ coverage, less poisoning for ORR, and thereby higher ORR activity. Our calculations provide support to the reported distribution of Ir within the sublayers. In particular, the total energies of the two $\mathrm{Pt}_{\mathrm{ML}} / \mathrm{PdIr}$ model slabs employed suggest that $\mathrm{Pd}$ is more stable in the first sublayer (right below the $\mathrm{Pt}_{\mathrm{ML}}$ ) than Ir is. Therefore, upon annealing, Pd atoms are pulled from the bulk to form a Pd-rich first sublayer right below the $\mathrm{Pt}$ surface monolayer, with an Ir-rich second sublayer found right below the first Pd sublayer.

This work suggests that the introduction of Ir to the subsurface of the Pd core successfully modified the electronic and geometric properties of the substrate for the $\mathrm{Pt}_{\mathrm{ML}}$, which in turns benefit the ORR kinetics.

\section{Other Modifications of Cores to Improve $\mathbf{P t}_{\mathrm{ML}}$ Electrocatalysts}

In addition to the above approaches, some of our efforts were also put on the study of unconventional core materials for $\mathrm{Pt}_{\mathrm{ML}}$. Two examples will be briefly shown here.

In addition to the conventional carbon-supported metallic nanoparticles, we found that intermetallic compound can be a great alternative as the substrate for $\mathrm{Pt}$ monolayer [59]. Some intermetallic compound nanoparticles are stable and highly active catalysts for small organic molecular oxidation $[60,61]$. Figure 21 shows the comparison of the 


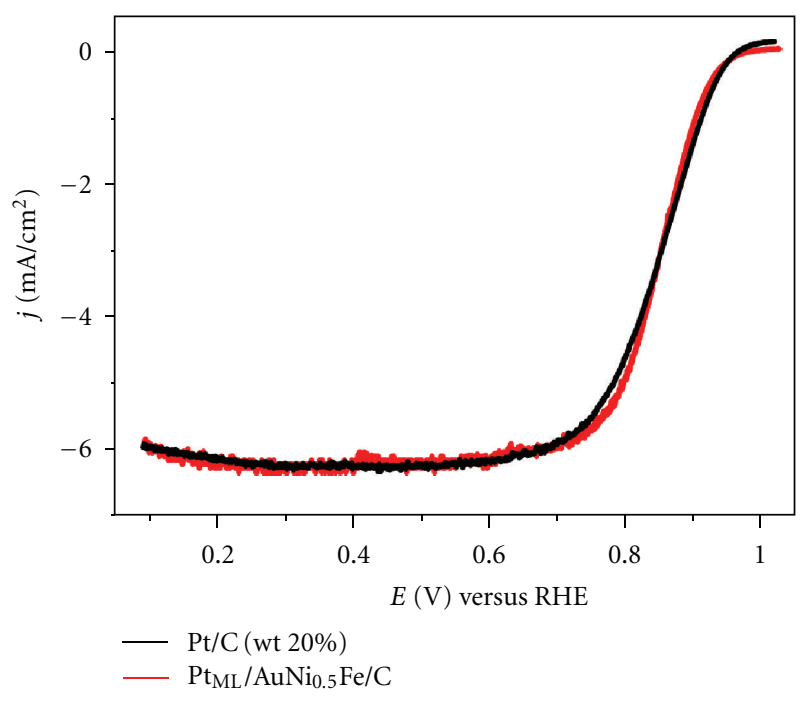

(a)

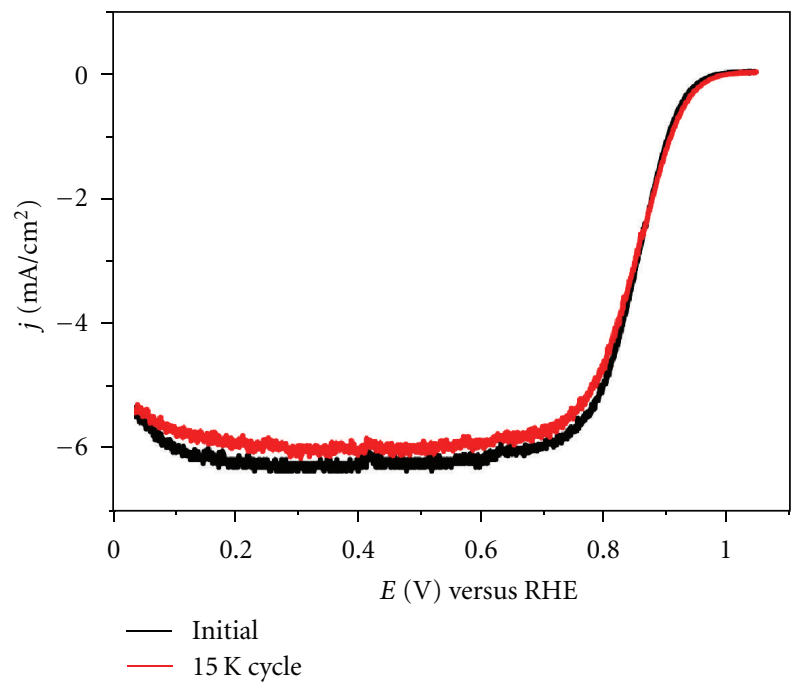

(b)

Figure 22: (a) Polarization curves of $\mathrm{Pt}_{\mathrm{ML}} / \mathrm{AuNi}_{0.5} \mathrm{Fe} / \mathrm{C}$ and $\mathrm{Pt} / \mathrm{C}$ in an oxygen-saturated $0.1 \mathrm{M} \mathrm{HClO}_{4}$; (b) polarization curves for $\mathrm{Pt}_{\mathrm{ML}} / \mathrm{AuNi}_{0.5} \mathrm{Fe} / \mathrm{C}$ before and after 15000 cycles of sweeping potentials between 0.6 and $1.0 \mathrm{~V}$ at $50 \mathrm{mV} / \mathrm{s}$. Conditions: scan rate, $10 \mathrm{mV} / \mathrm{s}$; rotation speed, $1600 \mathrm{rpm}[62]$.

TABLE 2: Binding energy (BE) of $\mathrm{OH}$ (in eV) on several close-packed (111) model surfaces at 1/6 ML coverage.

\begin{tabular}{cccccc}
\hline & $\mathrm{Pd}$ & $\mathrm{Pt}$ & $\mathrm{Pt}_{\mathrm{ML}} / \mathrm{Pd}$ & $\mathrm{Pt}_{\mathrm{ML}} / \mathrm{Pd} / \mathrm{PdIr}_{2} / \mathrm{Pd}$ & $\mathrm{Pt}_{\mathrm{ML}} / \mathrm{PdIr} / \mathrm{Pd}_{2}$ \\
\hline $\mathrm{BE}_{\mathrm{OH}}(\mathrm{eV})$ & -2.29 & -2.17 & -2.07 & -2.00 & -2.21 \\
\hline
\end{tabular}

Zero of the energy scale corresponds to $\mathrm{OH}(\mathrm{g})$ and the respective metal slab at infinite separation from each other. $\mathrm{Pt}_{\mathrm{ML}} / \mathrm{Pd} / \mathrm{PdIr}_{2} / \mathrm{Pd}$ represents the synthesized annealed catalyst $\left(\mathrm{Pt}_{\mathrm{ML}} \mathrm{PdIr}\right)$ whereas $\mathrm{Pt}_{\mathrm{ML}} / \mathrm{PdIr}_{2} / \mathrm{Pd}$ would be the expected catalyst without annealing $\left(\mathrm{Pt}_{\mathrm{ML}} \mathrm{IrPd}\right)$. The $\mathrm{BE}$ of $\mathrm{OH}$ on other relevant model systems is provided for comparison [58].

ORR activity of the $\mathrm{Pt}_{\mathrm{ML}}$ electrocatalysts with intermetallic compound $\mathrm{PtPb}$ and $\mathrm{PdFe}$ cores with the standard $\mathrm{Pt} / \mathrm{C}$. The activity of the $\mathrm{Pt} / \mathrm{C}$ is inferior to those $\mathrm{Pt}_{\mathrm{ML}}$ intermetallics. It demonstrated that the combination of highly stable, inexpensive intermetallics with $\mathrm{Pt}$ monolayer is promising in the design of electrocatalysts with high activity, low metal content, and high stability.

Another example is using multimetallic nanoparticles as the substrate for Pt monolayer. Our study on $\mathrm{Pt}_{\mathrm{ML}} / \mathrm{AuNi}_{0.5} \mathrm{Fe} / \mathrm{C}$ [62] demonstrated that by choosing proper combination of metals, the multimetallic core materials can be a promising substrate for $\mathrm{Pt}_{\mathrm{ML}}$ for the ORR from the synergetic contribution from each metal component. Figure 22 shows the ORR activity (a) and stability (b) of this catalyst. 5- and 7-fold increase in the Pt mass and specific activities, respectively, compared with $\mathrm{Pt} / \mathrm{C}$ and an insignificant loss in the electrochemical surface area and almost unchanged activity were achieved.

\section{Summary}

This review demonstrates that the ORR activity of $\mathrm{Pt}_{\mathrm{ML}}$ electrocatalysts can be further improved by the modification of surface and subsurface of the core materials. The removal of surface low-coordination sites, generation (via addition or segregation) of an interlayer between $\mathrm{Pt}_{\mathrm{ML}}$ and the core, or the introduction of a second metal component to the subsurface layer of the core can further improve the ORR activity and/or stability of $\mathrm{Pt}_{\mathrm{ML}}$ electrocatalysts. These modifications generate the alternation of the interactions between the substrate and the $\mathrm{Pt}_{\mathrm{ML}}$, involving the changes on both electronic (ligand) and geometric (strain) properties of the substrates. The improvements resulted from the application of these approaches provide a new perspective to designing of the new generation $\mathrm{Pt}_{\mathrm{ML}}$ electrocatalysts.

\section{Acknowledgment}

This paper is supported by US Department of Energy (DOE), Divisions of Chemical and Material Sciences, under Contract no. DE-AC02-98CH10886.

\section{References}

[1] R. R. Adzic, J. Zhang, K. Sasaki et al., "Platinum monolayer fuel cell electrocatalysts," Topics in Catalysis, vol. 46, no. 3-4, pp. 249-262, 2007.

[2] S. R. Brankovic, J. X. Wang, and R. R. Adžić, "Metal monolayer deposition by replacement of metal adlayers on electrode surfaces," Surface Science, vol. 474, no. 1-3, pp. L173-L179, 2001.

[3] J. Zhang, F. H. B. Lima, M. H. Shao et al., "Platinum monolayer on nonnoble metal-noble metal core-shell nanoparticle electrocatalysts for $\mathrm{O}_{2}$ reduction," Journal of Physical Chemistry B, vol. 109, no. 48, pp. 22701-22704, 2005. 
[4] J. Zhang, M. B. Vukmirovic, K. Sasaki, A. U. Nilekar, M. Mavrikakis, and R. R. Adzic, "Mixed-metal Pt monolayer electrocatalysts for enhanced oxygen reduction kinetics," Journal of the American Chemical Society, vol. 127, no. 36, pp. 12480-12481, 2005.

[5] J. Zhang, M. B. Vukmirović, K. Sasaki, F. Uribe, and R. R. Adžić, "Platinum monolayer electrocatalysts for oxygen reduction: effect of substrates, and long-term stability," Journal of the Serbian Chemical Society, vol. 70, no. 3, pp. 513-525, 2005.

[6] J. Zhang, M. B. Vukmirovic, Y. Xu, M. Mavrikakis, and R. R. Adzic, "Controlling the catalytic activity of platinummonolayer electrocatalysts for oxygen reduction with different substrates," Angewandte Chemie International Edition, vol. 44, no. 14 , pp. 2132-2135, 2005.

[7] M. Shao, K. Sasaki, N. S. Marinkovic, L. Zhang, and R. R. Adzic, "Synthesis and characterization of platinum monolayer oxygen-reduction electrocatalysts with Co-Pd core-shell nanoparticle supports," Electrochemistry Communications, vol. 9, no. 12, pp. 2848-2853, 2007.

[8] M. H. Shao, K. Sasaki, P. Liu, and R. R. Adzic, "Pd3Fe and Pt monolayer-modified Pd3Fe electrocatalysts for oxygen reduction," Zeitschrift fur Physikalische Chemie, vol. 221, no. 9-10, pp. 1175-1190, 2007.

[9] M. B. Vukmirovic, J. Zhang, K. Sasaki et al., "Platinum monolayer electrocatalysts for oxygen reduction," Electrochimica Acta, vol. 52, no. 6, pp. 2257-2263, 2007.

[10] K. Sasaki, L. Zhang, and R. R. Adzic, "Niobium oxidesupported platinum ultra-low amount electrocatalysts for oxygen reduction," Physical Chemistry Chemical Physics, vol. 10, no. 1, pp. 159-167, 2008.

[11] A. U. Nilekar, Y. Xu, J. Zhang et al., "Bimetallic and ternary alloys for improved oxygen reduction catalysis," Topics in Catalysis, vol. 46, pp. 276-284, 2007.

[12] Y. Xu, A. V. Ruban, and M. Mavrikakis, "Adsorption and dissociation of $\mathrm{O}_{2}$ on Pt-Co and Pt-Fe alloys," Journal of the American Chemical Society, vol. 126, no. 14, pp. 4717-4725, 2004.

[13] J. X. Wang, H. Inada, L. Wu et al., "Oxygen reduction on well-defined core-shell nanocatalysts: particle size, facet, and Pt shell thickness effects," Journal of the American Chemical Society, vol. 131, no. 47, pp. 17299-17302, 2009.

[14] E. Santos, P. Quaino, and W. Schmickler, "On the electrocatalysis of nanostructures: monolayers of a foreign atom (Pd) on different substrates M(lllll 11 )," Electrochimica Acta, vol. 55, no. 14, pp. 4346-4352, 2010.

[15] B. Hammer and J. K. Nørskov, "Theoretical surface science and catalysis-calculations and concepts," in Advances in Catalysis, C. G. Bruce and K. Helmut, Eds., vol. 45, pp. 71129, Academic Press, 2000.

[16] M. Shao, P. Liu, J. Zhang, and R. Adzic, "Origin of enhanced activity in palladium alloy electrocatalysts for oxygen reduction reaction," Journal of Physical Chemistry B, vol. 111, no. 24, pp. 6772-6775, 2007.

[17] J. Greeley and M. Mavrikakis, "Alloy catalysts designed from first principles," Nature Materials, vol. 3, pp. 810-815, 2004.

[18] J. Greeley, J. K. Nørskov, and M. Mavrikakis, "Electronic structure and catalysis on metal surfaces," Annual Review of Physical Chemistry, vol. 53, pp. 319-348, 2002.

[19] M. H. Shao, T. Huang, P. Liu et al., "Palladium monolayer and palladium alloy electrocatalysts for oxygen reduction," Langmuir, vol. 22, no. 25, pp. 10409-10415, 2006.

[20] N. M. Marković, H. A. Gasteiger, B. N. Grgur, and P. N. Ross, "Oxygen reduction reaction on $\mathrm{Pt}(111)$ : effects of bromide,"
Journal of Electroanalytical Chemistry, vol. 467, no. 1, pp. 157163, 1999.

[21] V. Stamenkovic, B. S. Mun, K. J. J. Mayrhofer et al., "Changing the activity of electrocatalysts for oxygen reduction by tuning the surface electronic structure," Angewandte Chemie International Edition, vol. 45, no. 18, pp. 2897-2901, 2006.

[22] Y. Cai, C. Ma, Y. Zhu, J. X. Wang, and R. R. Adzic, "Lowcoordination sites in oxygen-reduction electrocatalysis: their roles and methods for removal," Langmuir, vol. 27, no. 13, pp. 8540-8547, 2011.

[23] K. J. J. Mayrhofer, B. B. Blizanac, M. Arenz, V. R. Stamenkovic, P. N. Ross, and N. M. Markovic, "The impact of geometric and surface electronic properties of Pt-catalysts on the particle size effect in electrocatalysis," Journal of Physical Chemistry B, vol. 109, no. 30, pp. 14433-14440, 2005.

[24] A. Carrasquillo, J. J. Jeng, R. J. Barriga, W. F. Temesghen, and M. P. Soriaga, "Electrode-surf ace coordination chemistry: ligand substitution and competitive coordination of halides at well-defined Pd(100) and Pd(111) single crystals," Inorganica Chimica Acta, vol. 255, no. 2, pp. 249-254, 1997.

[25] E. Budevski, G. Staikov, and W. J. Lorenz, Electrochemical Phase Formation and Growth-An Introduction to the Initial Stages of Metal Deposition, VCH Verlagsgesellschaft $\mathrm{mbH}$, Weinheim, Germany, 1996.

[26] J. X. Wang, N. M. Markovic, and R. R. Adzic, "Kinetic analysis of oxygen reduction on $\mathrm{Pt}(111)$ in acid solutions: intrinsic kinetic parameters and anion adsorption effects," Journal of Physical Chemistry B, vol. 108, no. 13, pp. 4127-4133, 2004.

[27] P. W. Voorhees, "The theory of Ostwald ripening," Journal of Statistical Physics, vol. 38, no. 1-2, pp. 231-252, 1985.

[28] K. Gong, W. F. Chen, K. Sasaki et al., "Platinum-monolayer electrocatalysts: palladium interlayer on IrCo alloy core improves activity in oxygen-reduction reaction," Journal of Electroanalytical Chemistry, 2010.

[29] D. A. J. Rand and R. Woods, "Cyclic voltommetric studies on Iridium electrodes in sulfuric acid solutions-nature of oxygen layer and metal dissolution," Journal of Electroanalytical Chemistry, vol. 55, pp. 375-381, 1974.

[30] F. J. Vidal-Iglesias, J. Solla-Gullón, V. Montiel, J. M. Feliu, and A. Aldaz, "Screening of electrocatalysts for direct ammonia fuel cell: ammonia oxidation on PtMe (Me: Ir, Rh, Pd, Ru) and preferentially oriented $\operatorname{Pt}\left(\begin{array}{lll}1 & 0 & 0\end{array}\right)$ nanoparticles," Journal of Power Sources, vol. 171, no. 2, pp. 448-456, 2007.

[31] K. Lee, L. Zhang, and J. Zhang, "IrxCo ${ }_{1-x}(\mathrm{x}=0.3-1.0)$ alloy electrocatalysts, catalytic activities, and methanol tolerance in oxygen reduction reaction," Journal of Power Sources, vol. 170, no. 2, pp. 291-296, 2007.

[32] J. Greeley, I. E. L. Stephens, A. S. Bondarenko et al., "Alloys of platinum and early transition metals as oxygen reduction electrocatalysts," Nature Chemistry, vol. 1, no. 7, pp. 552-556, 2009.

[33] G. Kresse and J. Furthmüller, "Efficient iterative schemes for ab initio total-energy calculations using a plane-wave basis set," Physical Review B, vol. 54, no. 16, pp. 11169-11186, 1996.

[34] G. Kresse and J. Furthmüller, "Efficiency of ab-initio total energy calculations for metals and semiconductors using a plane-wave basis set," Computational Materials Science, vol. 6, pp. 15-50, 1996.

[35] J. P. Perdew, K. Burke, and M. Ernzerhof, "Generalized gradient approximation made simple," Physical Review Letters, vol. 77, no. 18, pp. 3865-3868, 1996.

[36] J. K. Nørskov, J. Rossmeisl, A. Logadottir et al., "Origin of the overpotential for oxygen reduction at a fuel-cell cathode," 
Journal of Physical Chemistry B, vol. 108, no. 46, pp. 1788617892, 2004.

[37] G. E. Ramírez-Caballero, Y. Ma, R. Callejas-Tovar, and P. B. Balbuena, "Surface segregation and stability of core-shell alloy catalysts for oxygen reduction in acid medium," Physical Chemistry Chemical Physics, vol. 12, no. 9, pp. 2209-2218, 2010.

[38] Y. Xing, Y. Cai, M. B. Vukmirovic et al., "Enhancing oxygen reduction reaction activity via $\mathrm{Pd}-\mathrm{Au}$ alloy sublayer mediation of Pt monolayer electrocatalysts," Journal of Physical Chemistry Letters, vol. 1, no. 21, pp. 3238-3242, 2010.

[39] L. Wang, A. Roudgar, and M. Eikerling, "Ab initio study of stability and site-specific oxygen adsorption energies of $\mathrm{Pt}$ nanoparticles," Journal of Physical Chemistry C, vol. 113, no. 42, pp. 17989-17996, 2009.

[40] Q. Jiang, L. H. Liang, and D. S. Zhao, "Lattice contraction and surface stress of fcc nanocrystals," Journal of Physical Chemistry B, vol. 105, no. 27, pp. 6275-6277, 2001.

[41] W. J. Huang, R. Sun, J. Tao, L. D. Menard, R. G. Nuzzo, and J. M. Zuo, "Coordination-dependent surface atomic contraction in nanocrystals revealed by coherent diffraction," Nature Materials, vol. 7, no. 4, pp. 308-313, 2008.

[42] J. Zhang, Y. Mo, M. B. Vukmirovic, R. Klie, K. Sasaki, and R. R. Adzic, "Platinum monolayer electrocatalysts for $\mathrm{O}_{2}$ reduction: $\mathrm{Pt}$ monolayer on $\mathrm{Pd}(111)$ and on carbonsupported Pd nanoparticles," Journal of Physical Chemistry B, vol. 108, no. 30, pp. 10955-10964, 2004.

[43] C. Wang, D. Van Der Vliet, K. L. More et al., "Multimetallic $\mathrm{Au} / \mathrm{FePt} 3$ nanoparticles as highly durable electrocatalyst," Nano Letters, vol. 11, no. 3, pp. 919-926, 2011.

[44] J. Zhang, K. Sasaki, E. Sutter, and R. R. Adzic, "Stabilization of platinum oxygen-reduction electrocatalysts using gold clusters," Science, vol. 315, no. 5809, pp. 220-222, 2007.

[45] W. Tang, S. Jayaraman, T. F. Jaramillo, G. D. Stucky, and E. W. McFarland, "Electrocatalytic activity of gold-platinum clusters for low temperature fuel cell applications," Journal of Physical Chemistry C, vol. 113, no. 12, pp. 5014-5024, 2009.

[46] J. B. Xu, T. S. Zhao, S. Y. Shen, and Y. S. Li, "Stabilization of the palladium electrocatalyst with alloyed gold for ethanol oxidation," International Journal of Hydrogen Energy, vol. 35, no. 13, pp. 6490-6500, 2010.

[47] W. P. Zhou, X. Yang, M. B. Vukmirovic et al., "Improving electrocatalysts for $\mathrm{O}_{2}$ reduction by fine-tuning the Pt-support interaction: Pt monolayer on the surfaces of a $\mathrm{Pd} 3 \mathrm{Fe}(111)$ single-crystal alloy," Journal of the American Chemical Society, vol. 131, no. 35, pp. 12755-12762, 2009.

[48] M. H. Shao, K. Sasaki, and R. R. Adzic, "Pd-Fe nanoparticles as electrocatalysts for oxygen reduction," Journal of the American Chemical Society, vol. 128, no. 11, pp. 3526-3527, 2006.

[49] J. L. Fernández, J. Michael White, Y. Sun, W. Tang, G. Henkelman, and A. J. Bard, "Characterization and theory of electrocatalysts based on scanning electrochemical microscopy screening methods," Langmuir, vol. 22, no. 25, pp. 1042610431, 2006.

[50] J. L. Fernández, V. Raghuveer, A. Manthiram, and A. J. Bard, "Pd-Ti and Pd-Co-Au electrocatalysts as a replacement for platinum for oxygen reduction in proton exchange membrane fuel cells," Journal of the American Chemical Society, vol. 127, no. 38, pp. 13100-13101, 2005.

[51] M. H. Shao, P. Liu, and R. R. Adzic, "Superoxide anion is the intermediate in the oxygen reduction reaction on platinum electrodes," Journal of the American Chemical Society, vol. 128, no. 23, pp. 7408-7409, 2006.
[52] N. Hoshi, K. Kagaya, and Y. Hori, "Voltammograms of the single-crystal electrodes of palladium in aqueous sulfuric acid electrolyte: $\operatorname{Pd}(\mathrm{S})-[\mathrm{n}(111) \times(111)]$ and $\operatorname{Pd}(\mathrm{S})-$ $[\mathrm{n}(100) \times(111)]$," Journal of Electroanalytical Chemistry, vol. 485 , no. 1 , pp. 55-60, 2000.

[53] N. Hoshi, M. Kuroda, and Y. Hori, "Voltammograms of stepped and kinked stepped surfaces of palladium: $\operatorname{Pd}(\mathrm{S})$ $[\mathrm{n}(111) \times(100)]$ and $\operatorname{Pd}(\mathrm{S})-[\mathrm{n}(100) \times(110)]$," Journal of Electroanalytical Chemistry, vol. 521, no. 1-2, pp. 155-160, 2002.

[54] M. Baldauf and D. M. Kolb, "A hydrogen adsorption and absorption study with ultrathin Pd overlayers on $\mathrm{Au}(111)$ and Au(100)," Electrochimica Acta, vol. 38, no. 15, pp. 2145-2153, 1993.

[55] M. Arenz, V. Stamenkovic, T. J. Schmidt, K. Wandelt, P. N. Ross, and N. M. Markovic, "CO adsorption and kinetics on well-characterized Pd films on Pt(l 111 ) in alkaline solutions," Surface Science, vol. 506, no. 3, pp. 287-296, 2002.

[56] V. R. Stamenkovic, B. Fowler, B. S. Mun et al., "Improved oxygen reduction activity on $\mathrm{Pt} 3 \mathrm{Ni}(111)$ via increased surface site availability," Science, vol. 315, no. 5811, pp. 493-497, 2007.

[57] V. R. Stamenkovic, B. S. Mun, K. J. J. Mayrhofer, P. N. Ross, and N. M. Markovic, "Effect of surface composition on electronic structure, stability, and electrocatalytic properties of Pt-transition metal alloys: Pt-skin versus Pt-skeleton surfaces," Journal of the American Chemical Society, vol. 128, no. 27, pp. 8813-8819, 2006.

[58] S. L. Knupp, M. B. Vukmirovic, P. Haldar, J. A. Herron, M. Mavrikakis, and R. R. Adzic, "Platinum monolayer electrocatalysts for $\mathrm{O}_{2}$ reduction: Pt monolayer on carbon-supported PdIr nanoparticles," Electrocatalysis, pp. 1-11, 2010.

[59] T. Ghosh, M. B. Vukmirovic, F. J. DiSalvo, and R. R. Adzic, "Intermetallics as novel supports for $\mathrm{Pt}$ monolayer $\mathrm{O}_{2}$ reduction electrocatalysts: potential for significantly improving properties," Journal of the American Chemical Society, vol. 132, no. 3, pp. 906-907, 2010.

[60] L. R. Alden, C. Roychowdhury, F. Matsumoto et al., "Synthesis, characterization, and electrocatalytic activity of $\mathrm{PtPb}$ nanoparticles prepared by two synthetic approaches," Langmuir, vol. 22, no. 25, pp. 10465-10471, 2006.

[61] C. Roychowdhury, F. Matsumoto, V. B. Zeldovich et al., "Synthesis, characterization, and electrocatalytic activity of PtBi and $\mathrm{PtPb}$ nanoparticles prepared by borohydride reduction in methanol," Chemistry of Materials, vol. 18, no. 14, pp. 33653372, 2006.

[62] K. Gong, D. Su, and R. R. Adzic, "Platinum-monolayer shell on AuNi0.5Fe nanoparticle core electrocatalyst with high activity and stability for the oxygen reduction reaction," Journal of the American Chemical Society, vol. 132, no. 41, pp. 14364-14366, 2010. 


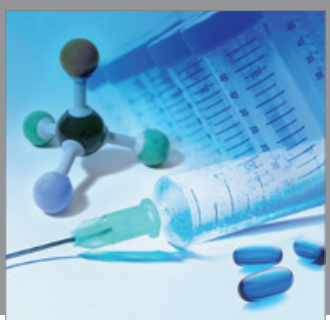

International Journal of

Medicinal Chemistry

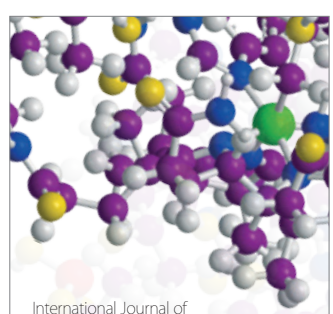

Carbohydrate Chemistry

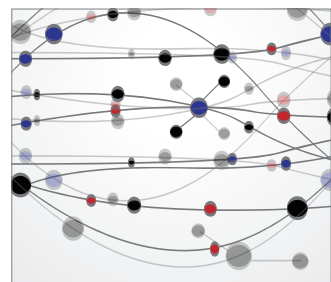

The Scientific World Journal
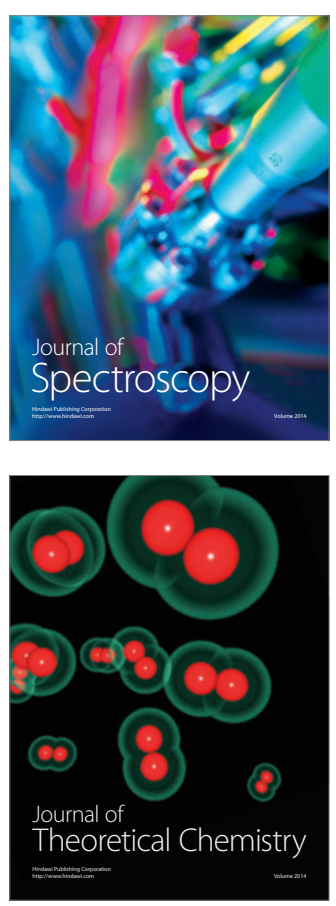
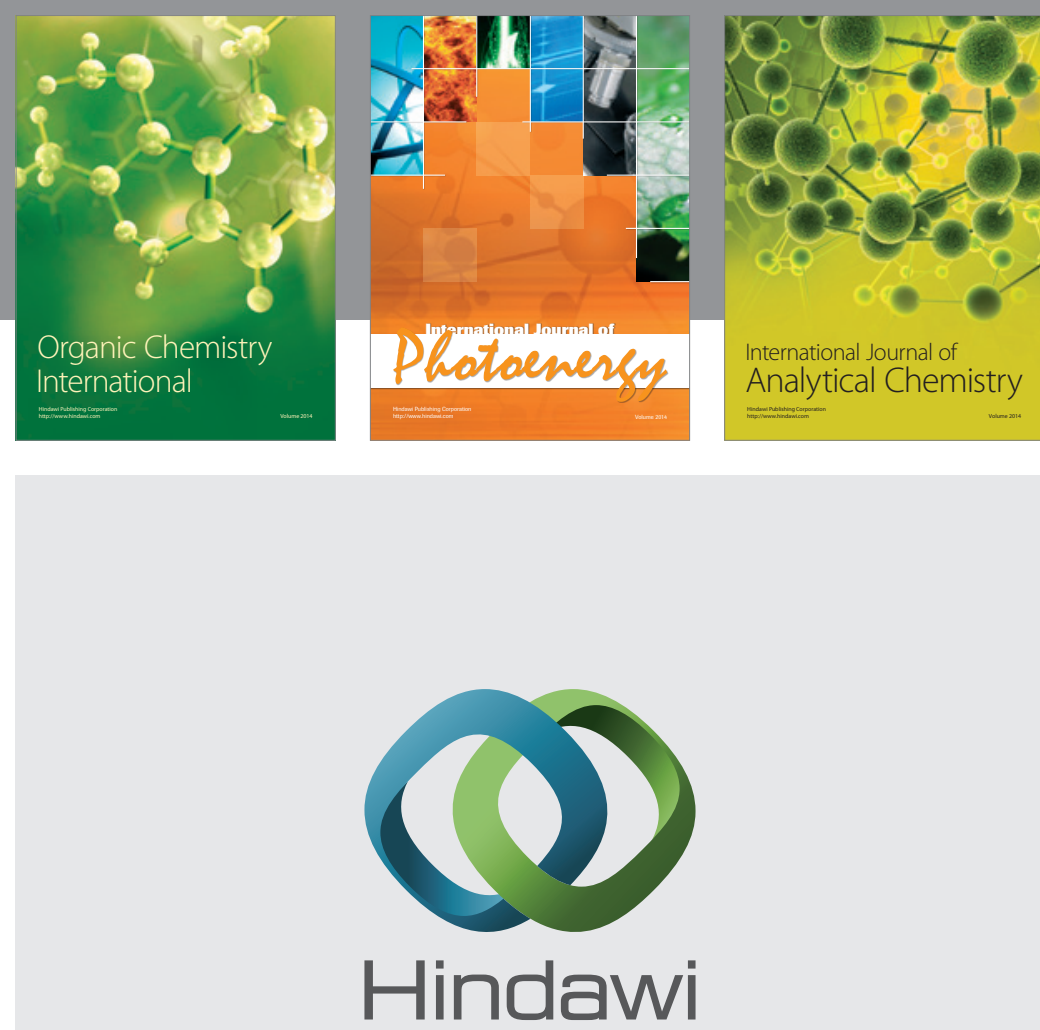

Submit your manuscripts at

http://www.hindawi.com
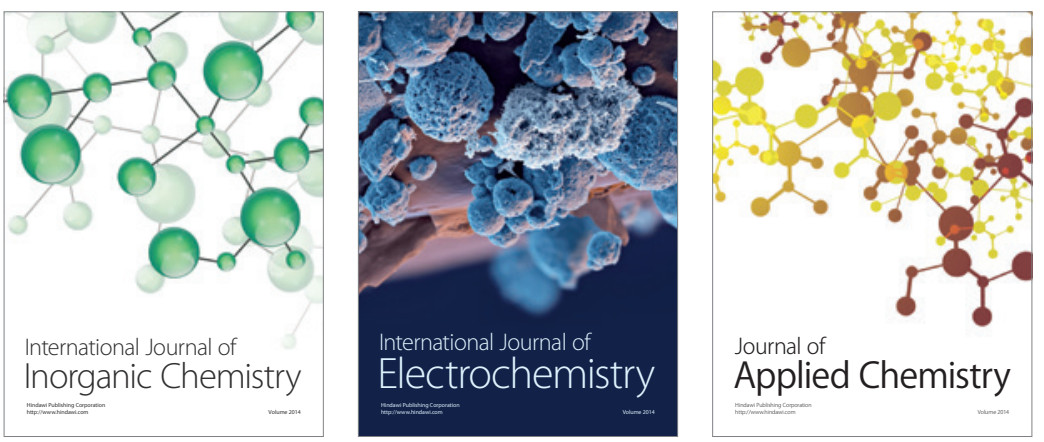

Journal of

Applied Chemistry
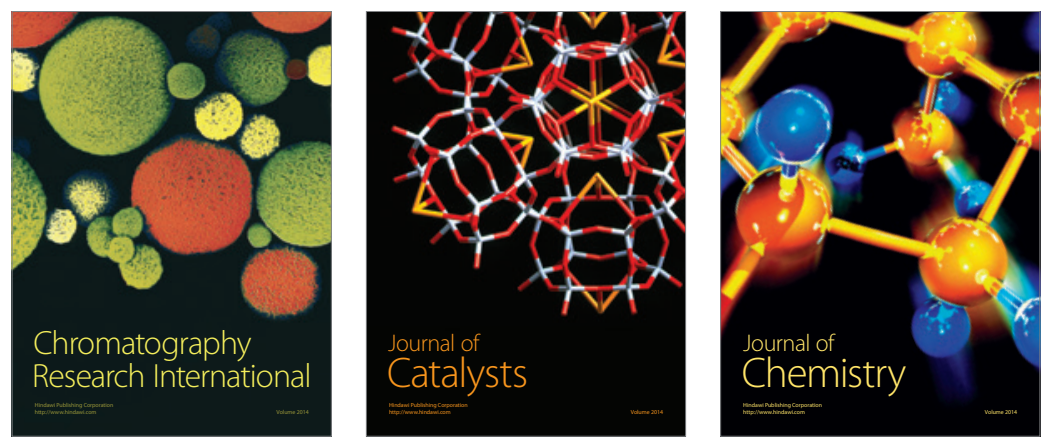
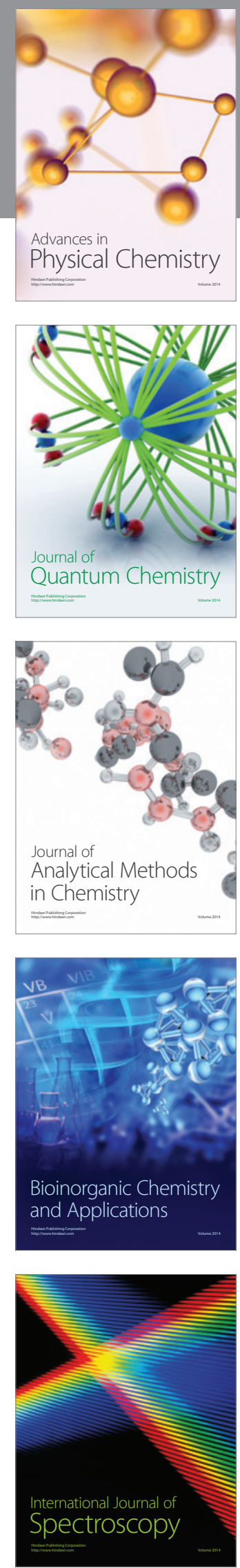